\title{
Seasonal Variations of the Mercury Multiple Isotopic Compositions of Subrural and Urban Aerosols Highlight an Additional Atmospheric $\mathbf{H g}^{\circ}$ Oxidation Pathway
}

OPEN ACCESS

Edited by:

Adrien Mestrot,

University of Bern, Switzerland

Reviewed by:

Carl Mitchell,

University of Toronto Scarborough,

Canada

Rute Isabel Cesário,

University of Lisbon, Portugal

*Correspondence:

David AuYang

auyangdavid@gmail.com

Jiubin Chen

jbchen@tju.edu.cn

Specialty section:

This article was submitted to

Biogeochemical Dynamics,

a section of the journal

Frontiers in Environmental Science

Received: 09 September 2021

Accepted: 07 December 2021

Published: 17 January 2022

Citation:

AuYang $D$, Chen J, Zheng $W$, Lang $Y$, Wang $Y$, Wang $Z$, Zhang $Y$, Liu $Y$,

Zhang $K$, Cai $H$, Yuan $W$ and Widory $D$

(2022) Seasonal Variations of the

Mercury Multiple Isotopic

Compositions of Subrural and Urban

Aerosols Highlight an Additional

Atmospheric $\mathrm{Hg}^{\circ}$ Oxidation Pathway.

Front. Environ. Sci. 9:773327.

doi: 10.3389/fenvs.2021.773327
David AuYang ${ }^{1 *}$, Jiubin Chen ${ }^{1,2 *}$, Wang Zheng ${ }^{2}$, Yunchao Lang ${ }^{2}$, Yina Wang ${ }^{3}$, Zhongwei Wang ${ }^{1}$, Yuanyuan Zhang ${ }^{1}$, Yulong Liu ${ }^{1}$, Ke Zhang ${ }^{2}$, Hongming Cai ${ }^{2}$, Wei Yuan ${ }^{2}$ and David Widory ${ }^{4}$

${ }^{1}$ State Key Laboratory of Environmental Geochemistry, Institute of Geochemistry, Chinese Academy of Sciences, Guiyang, China, ${ }^{2}$ Institute of Surface-Earth System Science, Tianjin University, Tianjin, China, ${ }^{3}$ Qiushi Honors College, Tianjin University, Tianjin, China, ${ }^{4}$ GEOTOP/ Université du Québec à Montreal, Montréal, QC, Canada

The mechanisms triggering the large variations in the mercury $(\mathrm{Hg})$ multiple isotopic compositions of atmospheric particle-bound $\mathrm{Hg}$ worldwide still remain unclear. The comparison of $\mathrm{Hg}$ isotopic compositions in aerosols collected in urban and rural areas may help distinguish the effects of natural processes from those of anthropogenic inputs. We thus investigated the $\mathrm{Hg}$ isotopic compositions of $\mathrm{PM}_{10}$ aerosols collected seasonally during 2015 at two monitoring stations on Montreal Island, one located downtown and the other in its westernmost subrural part, barely impacted by the city anthropogenic emissions. Our results show that, while $\mathrm{Hg}$ isotopic compositions present no seasonality at the urban station, possibly due to constant anthropogenic emissions, the subrural samples display clear seasonal variations, with higher $\Delta^{199} \mathrm{Hg}$ and $\Delta^{200} \mathrm{Hg}$ values (up to 0.77 and $0.12 \%$, respectively) during summer and close to $0 \%$ o during the rest of the year, that cannot solely be explained by anthropogenic primary emissions. Besides, $\Delta^{200} \mathrm{Hg}$ measured in the subrural aerosols display a positive correlation with $\mathrm{O}_{3}$ suggesting the implication of secondary processes involving ozone. We propose that the significant summer shift in the multiple $\mathrm{Hg}$ isotopic compositions may reflect a transition in the corresponding $\mathrm{Hg}^{\mathrm{O}}$ oxidation pathway, from halogens-triggered to ozone-dominated reactions. Still, this hypothesis needs to be further tested. Nevertheless, it demonstrates that $\mathrm{Hg}$ isotopes are effective at characterizing secondary processes that control its atmospheric budget, even at a local scale (i.e., urban vs subrural) and could thus be used to better constrain its atmospheric chemistry in various environments.

Keywords: mass-independent fractionation (MIF), mercury isotope, aerosols, oxidation, ozone 


\section{INTRODUCTION}

Mercury $(\mathrm{Hg})$ is a toxic element that has the ability to be remobilized at large scales in the atmosphere following successive oxidation and reduction reactions. Gaseous elemental mercury $\left(\mathrm{Hg}^{0}\right)$, the dominant $\mathrm{Hg}$ form in the atmosphere, is relatively stable and has a relatively long lifetime of 0.5 to 1 year that allows it to be transported over long distances worldwide (Selin 2009). $\mathrm{Hg}^{0}$ can be oxidized into reactive mercury $\left(\mathrm{Hg}^{\mathrm{II}}\right)$ through several possible pathways [e.g., $\mathrm{Si}$ et al. (2018)]. $\mathrm{Hg}^{\mathrm{II}}$ can then be incorporated into particles by adsorption [see Si et al. (2018)], forming particles bound mercury (PBM). Once deposited, $\mathrm{Hg}^{\mathrm{II}}$ may be transformed into methylmercury in aquatic system $\left(\mathrm{MeHg}^{+}\right)$that can then bioaccumulate in living aquatic organisms and ultimately impact Human health (Sunderland 2007). This emphasizes the need to better constrain the different oxidation pathways that $\mathrm{Hg}^{0}$ undergoes in the atmosphere. However, the dominant oxidation and reduction mechanisms controlling atmospheric $\mathrm{Hg}$, and their respective reaction rates, are still subject to debate (Saiz-Lopez et al., 2018) as discrepancies between the observed and modelled residence time and spatiotemporal distribution of $\mathrm{Hg}^{0}$ remain (Horowitz et al., 2017).

The study of the Hg isotopic systematics may help distinguish and identify the different oxidation pathways involved. $\mathrm{Hg}$ possesses seven stable isotopes, ${ }^{196} \mathrm{Hg},{ }^{198} \mathrm{Hg},{ }^{199} \mathrm{Hg},{ }^{200} \mathrm{Hg}$, ${ }^{201} \mathrm{Hg},{ }^{202} \mathrm{Hg}$, and ${ }^{204} \mathrm{Hg}$ with respective abundances of 0.15 , 9.97, 16.87, 23.10, 13.18, 29.86 and 6.87\%. Previous studies showed the $\mathrm{Hg}$ multi-isotopic compositions in particular the use of Mass dependent Fractionation and Mass Independent Fractionation (MDF and MIF respectively, see Methods for definitions) as powerful tracers of $\mathrm{Hg}$ sources, allowing the characterization of the processes that control $\mathrm{Hg}$ budget in the atmosphere (Rolison et al., 2013; Das et al., 2016; Fu et al., 2016; Yu et al., 2016; Zheng et al., 2016; Xu et al., 2017; Fu et al., 2019; Huang et al., 2019; Xu et al., 2019; Zhang et al., 2020). Previous studies have shown that aerosols collected in various regions are characterized by $\Delta^{199} \mathrm{Hg}$ varying from -1.50 to $1.50 \%, \Delta^{200} \mathrm{Hg}$ varying from -0.20 to $1.20 \%$ and $\Delta^{201} \mathrm{Hg}$ varying from -1.50 to 1.50\%o (Rolison et al., 2013; Das et al., 2016; Yu et al., 2016; Xu et al., 2017; Fu et al., 2019; Huang et al., 2019; Xu et al., 2019). Mass-Independent Fractionation of odd $\mathrm{Hg}$ isotopes (odd-MIF; i.e., $\Delta^{199} \mathrm{Hg}$ and $\Delta^{201} \mathrm{Hg}$ ) are mainly caused by the magnetic isotope effect (MIE) and the nuclear volume effects (NVE) (Bergquist et al., 2007; Buchachenko 2013; Cai et al., 2016) and are mainly produced during photochemical reduction of $\mathrm{Hg}^{2+}$, MeHg photo-demethylation, abiotic dark reduction and liquid-vapor evaporation (Bergquist et al., 2007; Estrade et al., 2009; Zheng et al., 2009; Zheng et al., 2010). These processes produce specific $\Delta^{199} \mathrm{Hg} / \Delta^{201} \mathrm{Hg}$ ratios, rendering this parameter a unique tool for characterizing the biogeochemical processes that $\mathrm{Hg}$ undergoes in the environment (Bergquist et al., 2007; Zheng et al., 2009; Sherman et al., 2010; Sun et al., 2016). On the other hand, the mechanisms triggering even-MIF (i.e., $\Delta^{200} \mathrm{Hg}$ and $\Delta^{204} \mathrm{Hg}$ ) that were reported in many atmosphere-related studies (Sherman et al., 2010; Chen et al., 2012; Wang et al., 2015; Yuan et al., 2015; Yuan et al., 2018) remain unknown, although some suggested that it may be related to the photochemical oxidation of elemental $\mathrm{Hg}^{0}$ in the tropopause (Chen et al., 2012) or to specific reactions (e.g., self shielding effect in compact fluorescent lamp (Mead et al., 2013) or a molecular magnetic isotope effect during $\mathrm{Hg}^{\mathrm{II}}$ photoreduction (Fu et al., 2021)). More recently, Sun et al. (2016) proposed that the oxidation of $\mathrm{Hg}^{0}$ by halogen atoms also produces both oddand even-MIF, suggesting the potential for oxidation reactions to trigger MIF of $\mathrm{Hg}$ isotopes, especially in atmospheric samples such as aerosols.

It must be noted that most of the reported odd and even-MIF measured in aerosols cannot be fully explained by these processes, and thus remain subject to debate. Atmospheric PBM results from 1) direct emissions of anthropogenic sources, whose contributions may account for $40 \%$ of the total PBM in polluted areas (Xiao et al., 1991) and/or 2) secondary atmospheric processes like a series of $\mathrm{Hg}$ oxidation by halogen atom and/or by $\mathrm{OH}$ followed by $\mathrm{Hg}$ photoreduction (Holmes et al., 2010; Subir et al., 2012; Horowitz et al., 2017). However, to our knowledge, only limited studies focused on the $\mathrm{Hg}$ multiple isotopic compositions of aerosols collected in moderately polluted or rural environments (Rolison et al., 2013; Yu et al., 2016; Fu et al., 2019) where the influence of those secondary processes (Holmes et al., 2010; Horowitz et al., 2017) remains rarely investigated (Fu et al., 2019; Huang et al., 2019). In particular, no study, to our knowledge, has yet been undertaken to compare the $\mathrm{Hg}$ isotopic compositions of aerosols collected in urban and subrural areas from a single region, although this should help distinguish the effects of natural processes from those of anthropogenic inputs. In this study, we investigated the $\mathrm{Hg}$ multiple isotopic compositions measured in aerosols collected over 1 year (i.e., covering the four seasons) at two different stations in Montreal (Canada), an urban and a sub-rural station, in order to constrain the respective impacts of natural and anthropogenic processes on the final $\mathrm{Hg}$ isotopic compositions, and to characterize potential mechanisms triggering their corresponding MIF.

\section{MATERIALS AND METHODS}

\subsection{Sampling Sites}

Montreal is considered a relatively lowly air-contaminated city, with an average annual $\mathrm{PM}_{10}$ (particles with an aerodynamical diameter $<10 \mu \mathrm{m}$ ) concentration of $16 \mu \mathrm{g} \mathrm{m}^{-3}$ (World Health Organization 2016), lower than the $20 \mu \mathrm{g} \mathrm{m}^{-3}$ guidelines set by the WHO. Still, the city exhibits local variations at several monitoring stations and records discrete episodes of air pollutions with concentrations exceeding the mean $50 \mu \mathrm{g} \mathrm{m}^{-3}$ 24-h guidelines (Boulet and Melancon, 2012; Boulet and Melancon, 2013). $\mathrm{PM}_{10}$ aerosols were sampled over a 1-year period in 2015 by the RSQA (Réseau de Surveillance de la Qualité de l'Air) in Montreal $\left(45^{\circ} \mathrm{N} 73^{\circ} \mathrm{W}\right.$, Canada) and its vicinity, in collaboration with the Ville de Montréal. Two monitoring stations (13 and 98) disseminated onto Montreal Island were selected for their specific environmental conditions (Figure 1). Station 13, referred as "Drummond," is located downtown and 


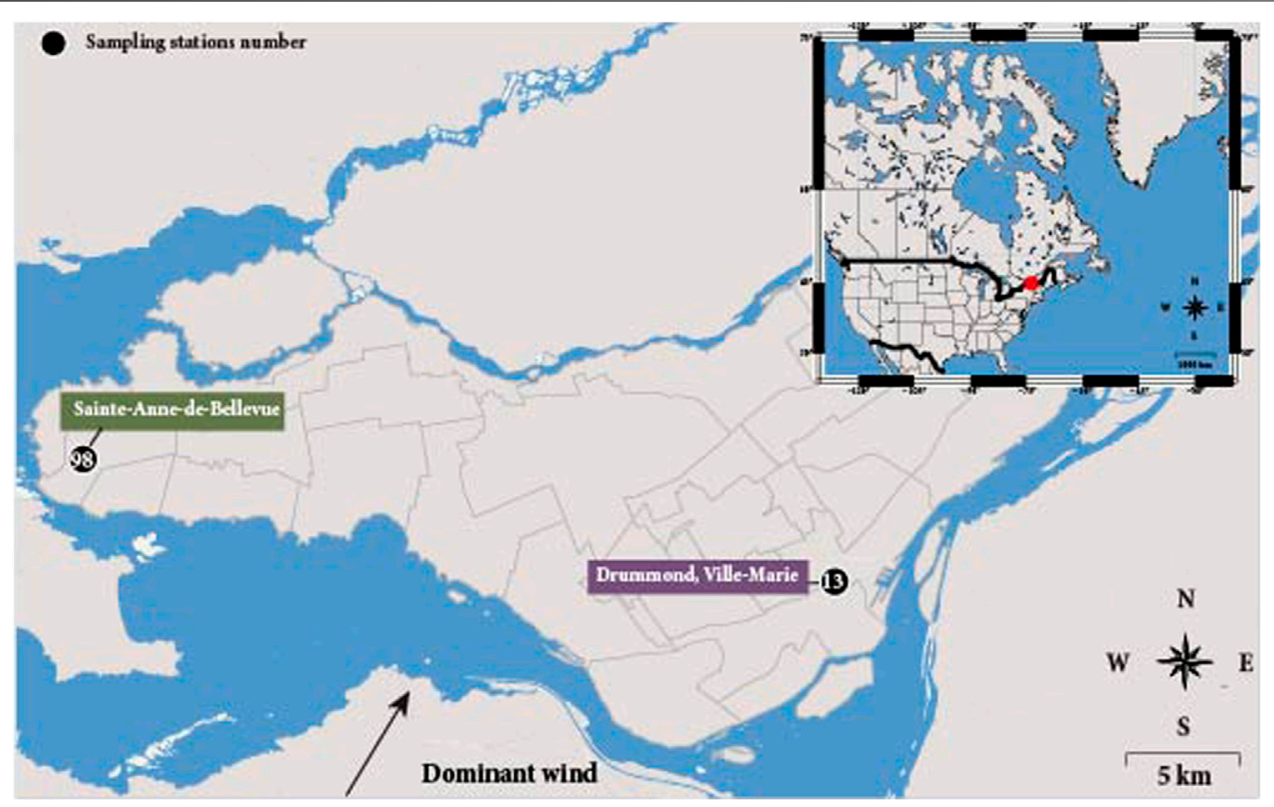

FIGURE 1 | Aerosols sampling locations in Montreal.

represents the urban background, whereas Station 98 referred as "Sainte-Anne de Bellevue" is located at the westernmost end of the island, in a semi-rural environment under dominant southwest-northeast blowing winds, and thus represents a station less impacted by local anthropogenic atmospheric emissions (Boulet and Melancon, 2012). Station 13 is thus expected to collect aerosols of both local and more distant sources, i.e., emitted locally and brought to Montreal, compared to station 98 where aerosols are expected to mostly come from outside the city. Our sampling strategy was thus designed to allow comparing a station mostly affected by local anthropogenic emissions to a station where aerosols are expected to have a remote origin (i.e., aerosols transported to Montreal). At this second station, aerosols are expected to at least partially derive from atmospheric secondary processes. In parallel, major pollutant gases, including ozone $\left(\mathrm{O}_{3}\right)$, sulfur dioxide $\left(\mathrm{SO}_{2}\right)$, nitrogen dioxide $\left(\mathrm{NO}_{2}\right)$, as well as $\mathrm{PM}_{2.5}$ hourly concentrations were continuously acquired from the Réseau de Surveillance de la Qualité de l'Air (RSQA) for both stations (http://ville.montreal.qc.ca/, last access: 02 January 2020). We calculated daily mean concentrations for each compound in order to fit with the $24 \mathrm{~h}$ sampling period of the aerosols.

$\mathrm{PM}_{10}$ samples and blank samples were also weekly collected by the RSQA on pre-combusted quartz filters using a high volume $\mathrm{PM}_{10}$ size selective inlet, with an average flow of $1.13 \mathrm{~m}^{3} \mathrm{~min}^{-1}$ for a period of $24 \mathrm{~h}$ (pumped air volume of $\sim 1627 \mathrm{~m}^{3}$ per filter). Within the sample set, four samples were selected and analyzed each month during an entire year, with two samples collected at station 13 and two others at station 98. Samples selected at each station were collected on the same day during the first 2 weeks of each month. Blank filters were analyzed randomly for each site, and yielded $\mathrm{Hg}$ concentrations under the analytical detection limit $(<0.1 \mathrm{ppb})$.
2.2 Elemental Concentration Measurement Concentrations of selected soluble inorganic species $\left(\mathrm{Na}^{2+}, \mathrm{K}^{+}\right.$, $\mathrm{Ca}^{2+}, \mathrm{Mg}^{2+}, \mathrm{NO}_{3}{ }^{-}, \mathrm{SO}_{4}{ }^{2-}, \mathrm{Cl}^{-}$) were measured using a Dionex ICS-90 Ion Chromatography system, after extraction from a $3 \mathrm{~cm} \times 3 \mathrm{~cm}$ filter piece with $30 \mathrm{ml}$ of Milli-Q water, following the method described by Paris et al. (2010). Detection limits for these ion species were usually in the order of $5 \mu \mathrm{g} \mathrm{L}^{-1}$, i.e., $0.1 \mathrm{ng} \mathrm{m}^{-3}$ considering our sampling and extraction protocols. Hg concentrations were measured by cold vapor atomic fluorescence spectroscopy (CVAFS, Tekran 2500) after reducing an aliquot of the pre-concentrated $\mathrm{Hg}^{\mathrm{II}}$ (i.e., acid trap solution) into $\mathrm{Hg}^{0}$ using $\mathrm{SnCl}_{2}$. The $\mathrm{Hg}^{0}$ was then collected on a gold-coated bead trap and analyzed by CVAFS (Huang et al., 2015).

\subsection{Hg Multiple Isotopic Compositions Measurement}

Aerosol filters were combusted using the dual-stage protocol described in Huang et al. (2015) to concentrate Hg. Briefly, each filter was introduced into a quartz tube that then underwent two successive combustions first at $950^{\circ} \mathrm{C}$, followed by a combustion at $1000^{\circ} \mathrm{C}$ for a total time of $3.5 \mathrm{~h}$ to decompose the $\mathrm{Hg}^{\mathrm{II}}$ present under the form of $\mathrm{Hg}_{\mathrm{p}}$ into vapor $\mathrm{Hg}^{0}$ (Sun et al., 2013). The combustion products, $\mathrm{Hg}^{0}$ (and other compounds if any), were purged using $\mathrm{Hg}$-free $\mathrm{O}_{2}$, and bubbled through a $5 \mathrm{ml}$ $\mathrm{HNO}_{3}-\mathrm{HCl}-\mathrm{H}_{2} \mathrm{O}$ mixture (2:4:9) acid trap (Sun et al., 2013; Huang et al., 2015). The generated solution was then transferred into a pre-cleaned glass bottle. $50 \mu \mathrm{l}$ of $0.2 \mathrm{M} \mathrm{BrCl}$ were then added to fully convert $\mathrm{Hg}^{0}$ into $\mathrm{Hg}^{\mathrm{II}}$.

$\mathrm{Hg}^{\mathrm{II}}$ was then converted back into $\mathrm{Hg}^{0}$ by reacting with $\mathrm{SnCl}_{2}$ and injected into a multi-collector inductively coupled plasma mass spectrometer (MC-ICPMS; Neptune plus) simultaneously 


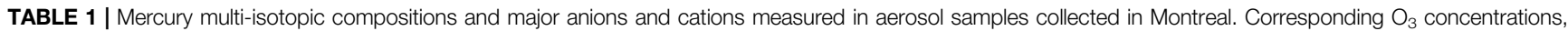
measured at station 13 , are also reported.

\begin{tabular}{|c|c|c|c|c|c|c|c|c|c|c|c|c|c|c|c|}
\hline \multicolumn{16}{|c|}{ Station 13} \\
\hline \multirow[t]{3}{*}{ Date } & $\mathrm{Hg}$ & $\delta^{202} \mathrm{Hg}$ & $\Delta^{201} \mathrm{Hg}$ & $\Delta^{200} \mathrm{Hg}$ & $\Delta^{199} \mathrm{Hg}$ & $\mathrm{Cl}^{-}$ & $\mathrm{NO}_{3}^{-}$ & $\mathrm{SO}_{4}{ }^{2-}$ & $\mathrm{Ca}^{2+}$ & $\mathbf{K}^{+}$ & $\mathrm{Mg}^{2+}$ & $\mathrm{Na}^{2+}$ & $\mathrm{O}_{3}$ & NO & $\mathrm{NO}_{2}$ \\
\hline & ng. $\mathrm{m}^{-3}$ & \pm & \pm & \pm & \pm & ng. $\mathrm{m}^{-3}$ & $\overline{\mathrm{ng} \cdot \mathrm{m}^{-3}}$ & $\overline{\text { ng.m }} \mathrm{m}^{-3}$ & $\mathrm{ng} \cdot \mathrm{m}^{-3}$ & $\overline{\mathrm{ng} \cdot \mathrm{m}^{-3}}$ & ng.m m $^{-3}$ & $\mathrm{ng} \cdot \mathrm{m}^{-3}$ & ppb & ppb & ppb \\
\hline & & $\begin{array}{c}0.1 \% \circ \\
(1 \sigma)\end{array}$ & $\begin{array}{c}0.02 \% \\
(1 \sigma)\end{array}$ & $\begin{array}{c}0.02 \% \text { o } \\
(1 \sigma)\end{array}$ & $\begin{array}{c}0.01 \% \text { o } \\
(1 \sigma)\end{array}$ & & & & & & & & & & \\
\hline $12-01-15$ & 35.7 & -4.0 & 0.01 & 0.04 & 0.18 & 6.35 & 11.04 & 7.21 & 9.61 & 0.68 & 0.14 & 12.52 & 13.1 & 14.7 & 23.6 \\
\hline $17-01-15$ & 1481.7 & -2.9 & -0.06 & 0.04 & -0.02 & 7.95 & 16.48 & 10.31 & 7.26 & 1.06 & 0.28 & 14.17 & 20.9 & 6.7 & 16.8 \\
\hline $17-02-15$ & 240.3 & -2.3 & 0.02 & 0.04 & 0.03 & 43.19 & 14.03 & 10.09 & 6.72 & 1.18 & 0.32 & 38.52 & 10.6 & 24.0 & 30.1 \\
\hline $23-02-15$ & 3289.2 & -2.2 & -0.06 & 0.00 & 0.00 & 10.22 & 3.80 & 7.53 & 4.71 & 0.64 & 0.19 & 11.36 & 18.9 & 10.1 & 12.7 \\
\hline 01-03-15 & 419.6 & -2.5 & -0.05 & 0.01 & -0.01 & 36.11 & 16.17 & 11.68 & 7.09 & 1.12 & 0.25 & 35.67 & 28.9 & 3.7 & 21.7 \\
\hline 07-03-15 & 93.4 & -2.4 & -0.02 & 0.07 & -0.01 & 8.09 & 20.65 & 13.78 & 7.45 & 0.97 & 0.28 & 17.73 & 34.1 & 4.3 & 18.0 \\
\hline $06-04-15$ & 1660.5 & -2.0 & -0.03 & -0.01 & 0.01 & 5.00 & 7.45 & 7.82 & 6.86 & 0.55 & 0.15 & 8.47 & 26.3 & 4.8 & 16.2 \\
\hline $12-04-15$ & 789.7 & -3.0 & 0.06 & 0.05 & 0.09 & 0.67 & 6.20 & 5.83 & 6.68 & 0.47 & 0.16 & 4.50 & 36.2 & 2.4 & 8.8 \\
\hline $06-05-15$ & 263.4 & -2.1 & 0.04 & 0.04 & 0.11 & 0.97 & 5.32 & 5.31 & 6.72 & 0.63 & 0.22 & 4.22 & 25.8 & 12.1 & 18.2 \\
\hline $12-05-15$ & 378.6 & -1.6 & 0.03 & -0.04 & 0.03 & 0.38 & 4.82 & 6.93 & 4.88 & 0.56 & 0.13 & 4.77 & 21.2 & 8.8 & 12.0 \\
\hline $05-06-15$ & 311.1 & -2.5 & -0.01 & 0.02 & 0.07 & 0.42 & 6.04 & 5.42 & 8.28 & 0.60 & 0.20 & 3.81 & 20.7 & 8.2 & 17.6 \\
\hline $11-06-15$ & 773.6 & -1.6 & -0.01 & 0.02 & -0.02 & 0.35 & 2.09 & 5.01 & 6.04 & 0.73 & 0.18 & 4.09 & 23.5 & 7.1 & 11.0 \\
\hline $05-07-15$ & 22.1 & -1.3 & 0.09 & 0.03 & 0.18 & 0.41 & 3.59 & 3.86 & 4.60 & 0.69 & 0.12 & 4.13 & 23.8 & 2.4 & 7.7 \\
\hline $11-07-15$ & 74.6 & -2.2 & 0.32 & 0.04 & 0.32 & 0.23 & 3.29 & 4.11 & 5.34 & 0.72 & 0.14 & 4.02 & 31.9 & 3.3 & 9.2 \\
\hline 04-08-15 & 869.6 & -2.9 & -0.01 & 0.04 & 0.02 & 0.17 & 3.10 & 3.55 & 3.44 & 0.56 & 0.13 & 3.46 & 30.1 & 6.2 & 10.5 \\
\hline $10-08-15$ & 1454.0 & -2.7 & 0.01 & -0.01 & 0.02 & 0.70 & 5.09 & 5.56 & 8.30 & 0.57 & 0.38 & 3.78 & 17.1 & 8.3 & 12.9 \\
\hline 03-09-15 & 231.5 & -3.1 & 0.02 & 0.03 & 0.08 & 0.50 & 3.69 & 6.86 & 6.86 & 0.65 & 0.32 & 4.56 & 19.6 & 7.5 & 12.7 \\
\hline 09-09-15 & 381.2 & -3.2 & 0.02 & 0.02 & 0.02 & 0.43 & 4.13 & 10.53 & 8.77 & 1.02 & 0.38 & 5.78 & 22.0 & 8.0 & 14.8 \\
\hline 03-10-15 & 297.3 & -3.1 & 0.00 & 0.03 & 0.11 & 0.80 & 3.14 & 2.88 & 4.18 & 0.38 & 0.13 & 2.87 & 15.9 & 4.3 & 5.8 \\
\hline $09-10-15$ & 134.7 & -2.6 & 0.03 & 0.00 & 0.16 & 0.30 & 5.95 & 4.89 & 4.86 & 0.56 & 0.14 & 3.93 & 8.0 & 16.8 & 13.8 \\
\hline $02-11-15$ & 120.9 & -3.4 & -0.02 & 0.02 & 0.13 & 0.38 & 1.85 & 3.39 & 2.14 & 0.35 & 0.05 & 2.89 & 9.3 & 21.3 & 17.4 \\
\hline $08-11-15$ & 97.1 & -3.2 & 0.01 & 0.04 & 0.12 & 0.17 & 1.02 & 2.76 & 3.76 & 0.41 & 0.09 & 3.29 & 20.5 & 3.1 & 7.0 \\
\hline $02-12-15$ & 54.6 & -3.1 & 0.02 & 0.00 & 0.12 & 0.32 & 3.01 & 6.20 & 2.39 & 0.58 & 0.084 & 4.20 & 3.5 & 28.9 & 22.2 \\
\hline $08-12-15$ & 60.8 & -2.4 & 0.03 & 0.05 & 0.10 & 1.06 & 3.35 & 6.02 & 5.33 & 0.62 & 0.23 & 4.71 & 8.2 & 14.1 & 18.6 \\
\hline
\end{tabular}

with $\mathrm{Tl}$, which was used as an internal standard to correct for the instrumental mass bias (Blum et al., 2007; Yin et al., 2016). A high concentration of $\mathrm{Tl}(20 \mathrm{ppb})$ was injected with each sample to prevent the formation of $\mathrm{Hg}$ hybrids during the analysis (Yin et al., 2016). The faraday cups were positioned to collect ${ }^{198} \mathrm{Hg}$ (L3), ${ }^{199} \mathrm{Hg}$ (L2), ${ }^{200} \mathrm{Hg}$ (L1), ${ }^{201} \mathrm{Hg}(\mathrm{C}),{ }^{202} \mathrm{Hg}(\mathrm{H} 1),{ }^{203} \mathrm{Tl}(\mathrm{H} 2)$, and ${ }^{205} \mathrm{Tl}(\mathrm{H} 3)$. Hg multiisotopic compositions were then determined by standard bracketing using the Hg NIST 3133 international standard. The Hg isotopic compositions are expressed as (Blum et al., 2007):

$$
\delta^{\mathrm{x}} \mathrm{Hg}=\left[\frac{\left({ }^{\mathrm{x}} \mathrm{Hg} /{ }^{198} \mathrm{Hg}\right)_{\text {sample }}}{\left({ }^{\mathrm{x}} \mathrm{Hg} /{ }^{198} \mathrm{Hg}\right)_{\text {std }}}-1\right] \times 1000
$$

Where $\mathrm{x}=199,200,201,202,204$, and "std" is the NIST SRM $3133 \mathrm{Hg}$ international standard. In general, the $\mathrm{Hg}$ multiple isotopic ratios are related to each other according to their mass, called the mass-dependent fractionation (MDF), which is expressed as follows (Young et al., 2002; Dauphas et al., 2016):

$$
{ }^{\mathrm{y}} \alpha=\left({ }^{202} \alpha\right)^{\mathrm{y} \beta}
$$

Where ${ }^{y} \alpha$ is either ${ }^{199} \alpha,{ }^{200} \alpha,{ }^{201} \alpha$ or ${ }^{204} \alpha$ and ${ }^{y} \beta$ is either ${ }^{199} \beta,{ }^{200} \beta$, ${ }^{201} \beta$ or ${ }^{204} \beta$. The ${ }^{3 y} \beta$-exponent describes the relative fractionation of ${ }^{\mathrm{y}} \mathrm{Hg} /{ }^{198} \mathrm{Hg}$ compared to ${ }^{202} \mathrm{Hg} /{ }^{198} \mathrm{Hg}$ where ${ }^{199} \beta,{ }^{200} \beta,{ }^{201} \beta$ and ${ }^{204} \beta$-values are respectively $0.252,0.502,0.752$ and 1.493 under equilibrium (Blum et al., 2007). The $\alpha$-notation corresponds to the different isotopic fractionation factors between ${ }^{198} \mathrm{Hg}$ and any of the other isotopes. For the oxidation of $\mathrm{Hg}^{0}$ into $\mathrm{Hg}^{\mathrm{II}}$, a is defined as follows (expressed here for the oxidation of $\mathrm{Hg}^{0}$ into $\left.\mathrm{Hg}^{\mathrm{II}}\right)$ :

$$
{ }^{\mathrm{x}} \boldsymbol{\alpha}_{\mathrm{Hg}_{\mathrm{II}}-\mathrm{Hg}_{0}}=\frac{\left({ }^{\mathrm{x}} \mathrm{Hg} /{ }^{198} \mathrm{Hg}\right)_{\mathrm{Hg}_{\mathrm{II}}}}{\left({ }^{\mathrm{x}} \mathrm{Hg} /{ }^{198} \mathrm{Hg}\right)_{\mathrm{Hg}_{0}}}=\frac{\delta^{\mathrm{x}} \mathrm{Hg}_{\mathrm{Hg}_{\mathrm{II}}} 1000+1}{\delta^{\mathrm{x}} \mathrm{Hg}_{\mathrm{Hg} 0} 1000+1}
$$

Any deviation of the $\mathrm{Hg}$ isotopic ratios from MDF is defined as the mass-independent fractionation (MIF) and is represented by the "capital delta" notation $\left(\Delta^{\times} \mathrm{Hg}\right.$, in \%o) defined following (Farquhar and Wing, 2003; Blum et al., 2007):

$$
\begin{aligned}
& \Delta^{199} \mathrm{Hg}=1000 \times {\left[\left(\ln \left(\left\{\delta^{199} \mathrm{Hg} / 1000\right\}+1\right)\right)-0.2520\right.} \\
&\left.\left(\ln \left(\left\{\delta^{202} \mathrm{Hg} / 1000\right\}+1\right)\right)\right] \\
& \Delta^{200} \mathrm{Hg}=1000 \times {\left[\left(\ln \left(\left\{\delta^{200} \mathrm{Hg} / 1000\right\}+1\right)\right)-0.5024\right.} \\
&\left.\left(\ln \left(\left\{\delta^{202} \mathrm{Hg} / 1000\right\}+1\right)\right)\right] \\
& \Delta^{201} \mathrm{Hg}=1000 \times\left[\left(\ln \left(\left\{\delta^{200} \mathrm{Hg} / 1000\right\}+1\right)\right)-0.7520\right. \\
&\left.\left(\ln \left(\left\{\delta^{202} \mathrm{Hg} / 1000\right\}+1\right)\right)\right]
\end{aligned}
$$




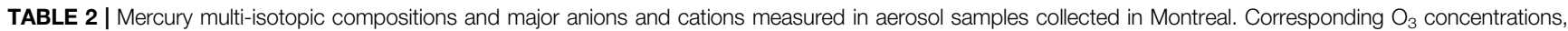
measured at station 98 , are also reported.

\begin{tabular}{|c|c|c|c|c|c|c|c|c|c|c|c|c|c|c|c|}
\hline \multicolumn{16}{|c|}{ Station 98} \\
\hline \multirow[t]{3}{*}{ Date } & $\mathrm{Hg}$ & $\delta^{202} \mathrm{Hg}$ & $\Delta^{201} \mathrm{Hg}$ & $\Delta^{200} \mathrm{Hg}$ & $\Delta^{199} \mathrm{Hg}$ & $\mathrm{Cl}^{-}$ & $\mathrm{NO}_{3}{ }^{-}$ & $\mathrm{SO}_{4}{ }^{2-}$ & $\mathrm{Ca}^{2+}$ & $\mathbf{K}^{+}$ & $\mathbf{M g}^{2+}$ & $\mathrm{Na}^{2+}$ & $\mathrm{O}_{3}$ & NO & $\mathrm{NO}_{2}$ \\
\hline & ng. $\mathrm{m}^{-3}$ & \pm & \pm & \pm & \pm & ng. $\mathrm{m}^{-3}$ & $\mathrm{ng} \cdot \mathrm{m}^{-3}$ & ng.m ${ }^{-3}$ & $n g \cdot m^{-3}$ & $n g \cdot m^{-3}$ & ng. $\mathrm{m}^{-3}$ & ng. $\mathrm{m}^{-3}$ & ppb & ppb & ppb \\
\hline & & $\begin{array}{c}0.1 \% \circ \\
(1 \sigma)\end{array}$ & $\begin{array}{c}0.02 \% \circ \\
(1 \sigma)\end{array}$ & $\begin{array}{c}0.02 \% \text { o } \\
(1 \sigma)\end{array}$ & $\begin{array}{c}0.01 \% \text { o } \\
(1 \sigma)\end{array}$ & & & & & & & & & & \\
\hline $12-01-15$ & 27.6 & -2.909 & -0.05 & 0.04 & -0.02 & 8.21 & 8.95 & 7.26 & 3.55 & 0.58 & 0.07 & 12.29 & 23.4 & 1.4 & 9.2 \\
\hline $17-01-15$ & 92.7 & -2.199 & 0.11 & 0.08 & 0.02 & 7.95 & 12.46 & 7.25 & 4.87 & 0.99 & 0.24 & 13.95 & 28.8 & 0.4 & 6.0 \\
\hline $17-02-15$ & 118.6 & -1.704 & 0.11 & 0.02 & 0.18 & 53.31 & 14.35 & 9.51 & 5.95 & 1.04 & 0.23 & 46.13 & 13.1 & 21.2 & 33.8 \\
\hline $23-02-15$ & 1019.9 & -2.510 & -0.03 & 0.02 & 0.00 & 13.91 & 2.76 & 5.87 & 3.60 & 0.60 & 0.18 & 13.94 & 24.7 & 0.4 & 4.9 \\
\hline 01-03-15 & 63.5 & -2.112 & -0.09 & 0.07 & -0.07 & 18.70 & 17.43 & 9.31 & 5.50 & 0.98 & 0.20 & 24.19 & 36.9 & 1.7 & 10.8 \\
\hline 07-03-15 & 140.1 & -2.144 & -0.08 & 0.05 & -0.04 & 0.51 & 21.86 & 13.44 & 5.71 & 0.87 & 0.30 & 14.83 & 43.8 & 0.3 & 5.7 \\
\hline $06-04-15$ & 239.1 & -2.567 & 0.04 & 0.03 & 0.05 & 0.93 & 9.92 & 5.35 & 7.75 & 0.51 & 0.14 & 5.99 & 29.1 & 1.0 & 7.1 \\
\hline $12-04-15$ & 677.5 & -2.057 & -0.06 & -0.01 & -0.03 & 0.15 & 5.19 & 6.53 & 4.04 & 0.50 & 0.10 & 5.32 & 40.0 & 0.2 & 2.2 \\
\hline $06-05-15$ & 14.7 & -3.389 & 0.16 & 0.02 & 0.37 & 0.47 & 5.97 & 4.50 & 4.44 & 0.84 & 0.21 & 5.87 & 31.9 & 2.6 & 7.3 \\
\hline $12-05-15$ & 1847.5 & -1.560 & -0.06 & 0.01 & 0.05 & 0.24 & 8.45 & 9.01 & 4.14 & 0.59 & 0.10 & 6.67 & 25.9 & 0.8 & 4.2 \\
\hline $05-06-15$ & 390.4 & -2.100 & -0.10 & -0.04 & -0.01 & 0.20 & 5.47 & 6.40 & 5.20 & 0.75 & 0.22 & 5.57 & 25.8 & 0.9 & 5.8 \\
\hline $11-06-15$ & 42.5 & -2.568 & 0.10 & 0.04 & 0.16 & 0.18 & 3.02 & 4.03 & 4.05 & 0.73 & 0.13 & 4.57 & 29.1 & 0.1 & 2.7 \\
\hline $05-07-15$ & 86.5 & -3.764 & 0.24 & 0.06 & 0.39 & 0.28 & 3.16 & 4.82 & 3.48 & 0.71 & 0.12 & 5.03 & 29.1 & 0.1 & 3.0 \\
\hline $11-07-15$ & 44.2 & -1.215 & 0.68 & 0.12 & 0.77 & 0.24 & 13.84 & 3.91 & 3.38 & 0.63 & 0.08 & 3.78 & 35.1 & 0.0 & 2.8 \\
\hline 04-08-15 & 315.9 & -2.510 & 0.01 & 0.04 & 0.01 & 0.14 & 3.40 & 2.43 & 2.58 & 0.37 & 0.06 & 2.78 & 26.5 & 0.2 & 2.6 \\
\hline $10-08-15$ & 79.3 & -2.423 & 0.31 & 0.07 & 0.19 & 0.33 & 6.64 & 4.17 & 4.76 & 0.62 & 0.17 & 3.92 & 30.4 & 1.8 & 4.3 \\
\hline 03-09-15 & 100.1 & -3.085 & 0.35 & 0.07 & 0.77 & 0.16 & 4.26 & 7.04 & 4.97 & 0.70 & 0.16 & 5.26 & 27.6 & 0.2 & 4.2 \\
\hline $09-09-15$ & 78.4 & -2.637 & 0.04 & 0.02 & 0.12 & 1.99 & 4.15 & 9.36 & 5.14 & 0.72 & 0.18 & 5.58 & 31.1 & 0.1 & 3.5 \\
\hline $03-10-15$ & 30.3 & -2.894 & 0.01 & 0.01 & 0.14 & 0.40 & 1.85 & 2.69 & 3.13 & 0.32 & 0.09 & 2.59 & 19.4 & 0.1 & 1.3 \\
\hline $09-10-15$ & 84.0 & -2.961 & 0.01 & -0.01 & 0.11 & 0.24 & 2.64 & 4.78 & 2.66 & 0.39 & 0.08 & 3.33 & 13.8 & 0.3 & 4.5 \\
\hline $08-11-15$ & 69.3 & -2.740 & -0.03 & 0.00 & 0.11 & 0.13 & 1.26 & 1.33 & 0.59 & 0.30 & 0.02 & 2.51 & 17.1 & 5.8 & 4.4 \\
\hline $14-11-15$ & 39.9 & -2.555 & 0.01 & 0.01 & 0.08 & 0.12 & 1.04 & 2.21 & 0.61 & 0.20 & 0.02 & 1.55 & 25.4 & 0.0 & 0.8 \\
\hline $02-12-15$ & 90.6 & -2.566 & 0.00 & -0.02 & 0.07 & 0.11 & 3.27 & 3.57 & 0.62 & 0.44 & 0.04 & 3.50 & 4.8 & 1.5 & 9.4 \\
\hline $08-12-15$ & 77.4 & -2.074 & -0.08 & -0.02 & 0.02 & 0.59 & 4.18 & 5.25 & 4.74 & 0.42 & 0.19 & 3.43 & 11.3 & 1.8 & 12.3 \\
\hline
\end{tabular}

The NIST 3177 standard was also regularly analyzed with concentrations matching those of the aerosol samples (i.e., $2 \mathrm{ppb}$ ) to control the instrument stability and to guarantee the measurement quality (Geng et al., 2018). Repeated analyses $(n=22)$ of the NIST 3177 standard yielded $\delta^{202} \mathrm{Hg}=-0.52 \pm$ $0.03 \%$ o $(2 \sigma), \Delta^{199} \mathrm{Hg}=-0.02 \pm 0.05 \%$ o $(2 \sigma), \Delta^{200} \mathrm{Hg}=0.01 \pm$ $0.03 \%$ o $(2 \sigma), \Delta^{201} \mathrm{Hg}=-0.01 \pm 0.02 \%$ o $(2 \sigma)$ relative to NIST 3133 , consistent with previous reported values (Wang et al., 2015; Chen et al., 2016; Sun et al., 2016; Yuan et al., 2018; Fu et al., 2019; Zhang et al., 2020). A Chinese loamy sand CRM024, used as a second certified reference material, with a $\mathrm{Hg}$ concentration of $0.71 \mathrm{ppm}$ was also analyzed $(n=8)$. The result yielded a recovery of $104 \pm 7 \%$ after pre-concentration by dual-stage combustion, and $\delta^{202} \mathrm{Hg}=-1.43 \pm 0.08 \%$ o $(2 \sigma), \Delta^{199} \mathrm{Hg}=0.03 \pm 0.02 \%$ o $(2 \sigma)$, $\Delta^{200} \mathrm{Hg}=-0.00 \pm 0.02 \%$ o $(2 \sigma), \Delta^{201} \mathrm{Hg}=0.00 \pm 0.01 \%$ o $(2 \sigma)$, in good agreement with the $\mathrm{Hg}$ isotopic compositions reported by Huang et al. (2015).

\subsection{HYSPLIT Back-Trajectories Modelling and Statistical Methods}

To investigate potential relationships between air masses and the aerosol $\mathrm{Hg}$ multi-isotopic compositions, we modelled daily $72 \mathrm{~h}$ back-trajectories at a $10 \mathrm{~m}$ agl height using HYSPLIT (Hybrid Single Particles Lagrangien Integrated Trajectory) for each sample. The model used NCEP-NCAR reanalysis data fields, using a 2.5-degree latitude-longitude global grid with a time resolution of $6 \mathrm{~h}$ obtained from the Air Resources Laboratory (ARL). Back-trajectories were ultimately incorporated into a map generated by GMT (Generic mapping tools).

The significance of each correlation was calculated using a Spearman Correlation, as this non-parametrical test does not carry any assumption about the data distribution and is not sensitive to outliers.

\section{RESULTS}

Mercury multi-isotopic compositions in aerosols from stations 13 and 98 are reported in Tables 1, 2, respectively. For downtown station $13(n=24), \delta^{202} \mathrm{Hg}$ vary from -4.00 to $-1.30 \%$ o with a mean value of $-2.65 \pm 0.63 \%$ o $(2 \sigma), \Delta{ }^{199} \mathrm{Hg}$ from -0.06 to $0.33 \%$ with a mean value of $0.08 \pm 0.08 \%$ o $(2 \sigma)$, $\Delta^{200} \mathrm{Hg}$ from -0.04 to $0.07 \%$ with a mean value of $0.02 \pm 0.02 \%$ $(2 \sigma)$ and $\Delta^{201} \mathrm{Hg}$ from -0.02 to $0.32 \%$ with a mean-value of $0.02 \pm 0.07 \%$ o $(2 \sigma)$. For subrural station $98(n=24), \delta^{202} \mathrm{Hg}$ vary from -3.70 to $-1.20 \%$ with a mean-value of $-2.46 \pm 0.56 \%$ o $(2 \sigma), \Delta^{199} \mathrm{Hg}$ from -0.07 to $0.78 \%$ with a mean-value of $0.14 \pm$ $0.22 \%$ o $(2 \sigma), \Delta^{200} \mathrm{Hg}$ from -0.04 to $0.12 \%$ with a mean-value of $0.03 \pm 0.04 \%$ o $(2 \sigma)$ and $\Delta^{201} \mathrm{Hg}$ from -0.10 to $0.69 \%$ with a mean-value of $0.06 \pm 0.18 \%$ o $(2 \sigma)$. A comparison with the values available in the literature is provided in the Supplementary 

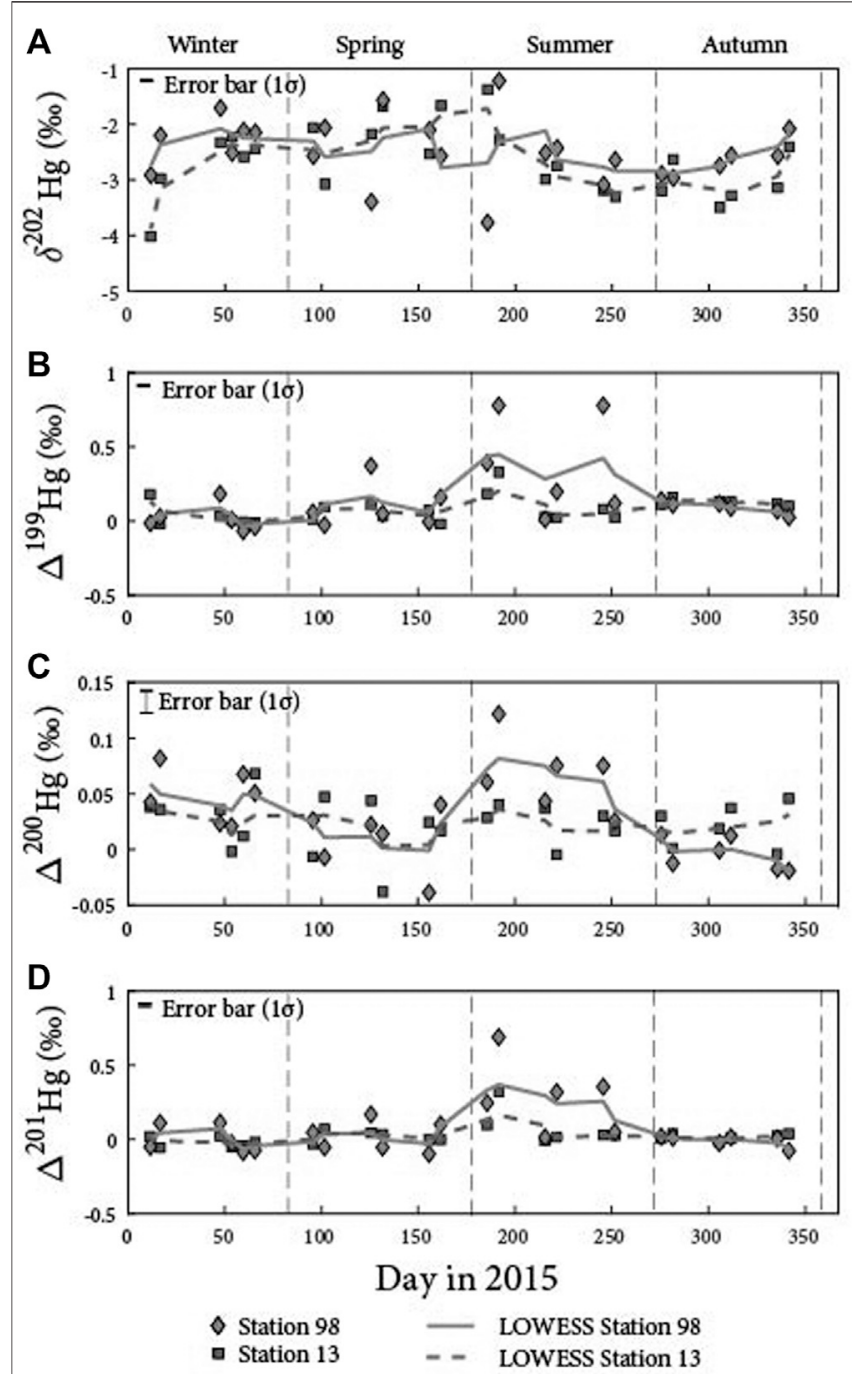

FIGURE 2 | Hg multi-isotopic compositions. (A) $\delta^{202} \mathrm{Hg}$, (B) $\Delta^{199} \mathrm{Hg}$, (C) $\Delta^{200} \mathrm{Hg}$ and (D) $\Delta^{201} \mathrm{Hg}$ time series in aerosols sampled in Montreal. Locally weighted scatter plot smoothing (LOWESS) is also shown for all $\mathrm{Hg}$ isotopic compositions.

Materials. Overall, the mean values for $\mathrm{Hg}$ isotope compositions are very close for each of the compared stations.

A locally weighted scatter plot smoothing (LOWESS) was applied to reveal seasonal variations in the $\mathrm{Hg}$ multi-isotopic compositions for each station (Figures 2A-D), as this nonparametric fitting provides a flexible approach to represent data without assuming the data must fit a particular type of distribution. As a result, station 98 presents a seasonality, with the highest values observed during summer for both odd $(0.78 \%$; $\Delta^{199} \mathrm{Hg}$ and $\left.\Delta^{201} \mathrm{Hg}\right)$ and even-MIF $\left(0.15 \%\right.$; $\left.\Delta^{200} \mathrm{Hg}\right)$, whereas station 13 does not present any seasonality. This suggests that distinct factors control the $\mathrm{Hg}$ isotope systematics at stations 13 and 98 .

Besides, station 13 is characterized by higher $\mathrm{NO}_{\mathrm{x}}\left(\mathrm{NO}+\mathrm{NO}_{2}\right)$ concentrations, varying from 10 to $54 \mathrm{ppb}$ with a mean of $24 \pm$ $11.8 \mathrm{ppb}$, whereas they vary from 0.8 to $54 \mathrm{ppb}$, with a mean of
$8 \pm 10.8 \mathrm{ppb}$, at station 98 (Tables 1, 2). We also observe that sulfate $\left(\mathrm{SO}_{4}{ }^{2-}\right)$ concentrations are significantly higher $(p$-values $=$ 0.01 ) at station 13 compared to station 98 , in agreement with the fact that station 13 is expected to be largely impacted by human activities (Tables 1, 2). Moreover, yearly ozone $\left(\mathrm{O}_{3}\right)$ concentrations are also significantly higher $(p$-values $<0.01)$ at station 98 compared to station 13, varying from 5 to $44 \mathrm{ppb}$ with a mean concentration of $26 \pm 9 \mathrm{ppb}$, and from 4 to $36 \mathrm{ppb}$ with a mean concentration of $20 \pm 8 \mathrm{ppb}$, respectively (Tables 1, 2).

\section{DISCUSSION}

The mechanisms of PBM formation are not well constrained as uncertainties remain on 1) the main $\mathrm{Hg}$ species (i.e., $\mathrm{Hg}^{0}$ or $\mathrm{Hg}^{\mathrm{II}}$ ) that are incorporated into PBM (Seigneur, 1998; Amos et al., 2012; Kurien et al., 2017) and 2) the eventual isotopic fractionation associated to the incorporation of $\mathrm{Hg}^{\mathrm{II}}$. In the following section, we will discuss the mechanisms and the main sources responsible for the variation of $\mathrm{Hg}$ isotopic compositions measured on PBM at stations 13 and 98, based on our dataset and the previous experimental results from the $\mathrm{Hg}^{0}$ oxidation and $\mathrm{Hg}^{\mathrm{II}}$ photoreduction that have been widely used in the literature to address the origin and possible impact factors of PBM (Huang et al., 2015; Huang et al. 2016; Huang et al. 2018; Fu et al., 2019; Huang et al., 2019; Qiu et al., 2021).

\subsection{Influence of Anthropogenic Emissions}

The both low odd and even-MIF, close to $0 \%$, coupled to the absence of $\mathrm{Hg}$ isotopic seasonality at station 13 , suggest that the factor controlling the $\mathrm{Hg}$ multi-isotopic compositions is constant and perennial during 2015. This contrasts with the seasonality in the $\mathrm{Hg}$ isotopic compositions previously reported in urban areas that has been demonstrated to reflect varying contributions from anthropogenic emission sources (Huang et al., 2016; Huang et al., 2018). Still, considering the geographical location of station 13, we hypothesize that the corresponding $\mathrm{Hg}$ isotopic compositions may be largely impacted by anthropogenic emissions. In fact, the low $\mathrm{Hg}$-MIF, in particular the $\Delta^{199} \mathrm{Hg}$ close to $0 \%$, and the negative $\delta^{202} \mathrm{Hg}$ measured at this station are characterized by values that are consistent and within the range of variations reported for anthropogenic emissions (Biswas et al., 2008, Sun et al., 2014, Yin et al., 2014, Wang et al., 2015, Das et al., 2016, Huang et al., 2016, Zheng et al., 2016, Wang T. et al., 2017; Wang T. et al., 2017, Huang et al., 2018, Yuan et al., 2018, Zhang et al., 2020). Moreover, we observe that the $\Delta^{199} \mathrm{Hg} / \Delta^{201} \mathrm{Hg}$ ratio, a proxy for identifying processes triggering $\mathrm{Hg}$-MIF (Bergquist et al., 2007; Zheng et al., 2009; Sherman et al., 2010; Sun et al., 2016) is characterized by a yearly value close to 0.95 at station 13 . A $\Delta^{199} \mathrm{Hg} / \Delta^{201} \mathrm{Hg}$ ratio ranging from 1 to 1.3 is generally explained as the result of photoreduction (Bergquist et al., 2007; Zheng et al., 2009). As seen, Supplementary Figure S1 reports a compilation of primary aerosols emitted by various emission sources and shows that anthropogenic PBM is characterized by a $\Delta^{199} \mathrm{Hg} / \Delta^{201} \mathrm{Hg}$ ratio of 1.075 , close to the $0.95 \Delta^{199} \mathrm{Hg} / \Delta^{201} \mathrm{Hg}$ ratio we observe at station 13 (Figure 3), 

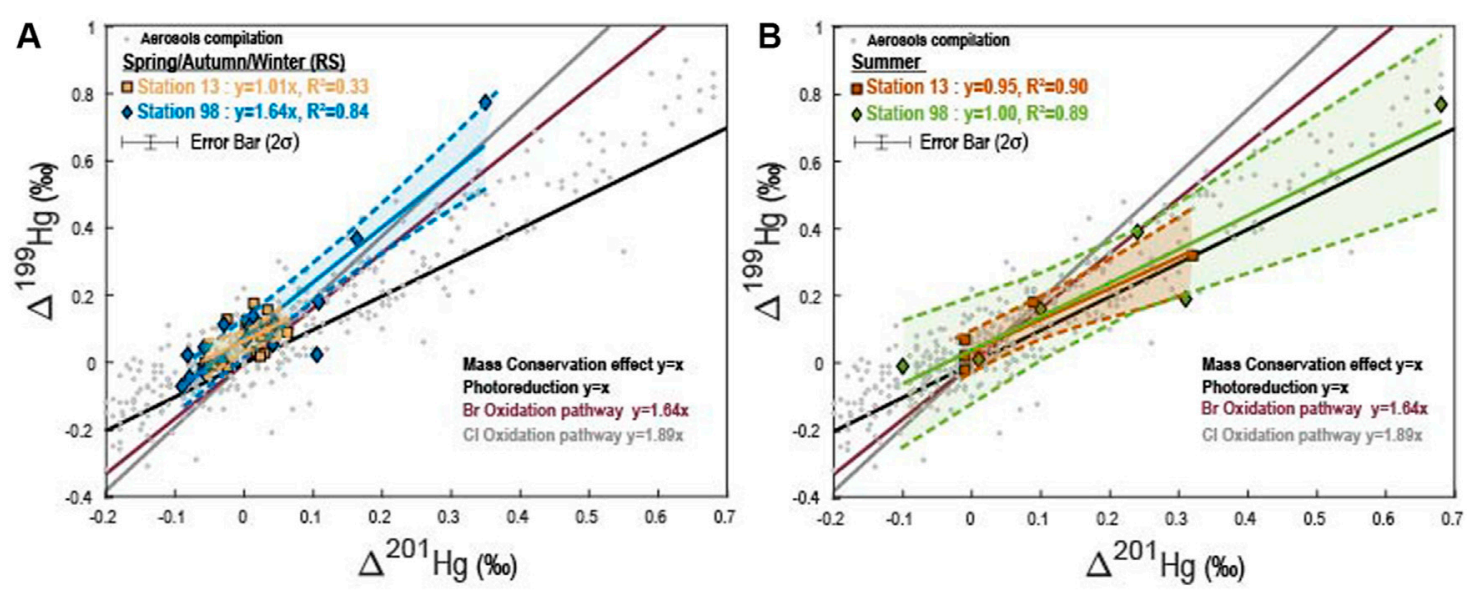

FIGURE 3 | Hg odd-MIF measured in Montreal aerosol samples. (A) Spring Autumn, Winter and (B) Summer. Data from the literature are also reported (Rolison et al., 2013; Huang et al., 2015; Das et al., 2016; Huang et al., 2016; Yu et al., 2016; Xu et al., 2017; Huang et al., 2018; Yuan et al., 2018; Fu et al., 2019; Huang et al., 2019; Xu et al., 2019). Slopes corresponding to Hg oxidation by $\mathrm{Br}$ or Cl atoms are taken from Sun et al. (2016). Slope for the photoreduction is from Bergquist et al. (2007), and that corresponding to the mass conservation effect is detailed in the Supplementary Materials.

implying probably a dominance of anthropogenic emissions while the implication of photoreduction cannot be rejected. Without further data, determining the respective contributions of primary (mixing) and secondary (photoreduction) $\mathrm{Hg}$ is difficult at this point. Moreover, as both mechanisms do not yield specific $\Delta^{200} \mathrm{Hg}$ variation in the $\Delta^{201} \mathrm{Hg} / \Delta^{200} \mathrm{Hg}$ and $\Delta^{199} \mathrm{Hg} / \Delta^{200} \mathrm{Hg}$ diagrams (Figure 4), even-MIF cannot be used to distinguish sources from process effects (Bergquist et al., 2007; Zheng et al., 2009). The identification of the different sources involved is not further discussed here as it is beyond the scope of our study. However, in the case of a dominance of anthropogenic emission, we suggest that the anthropogenic sources and their respective contributions are not expected to vary over time, as demonstrated by the absence of $\mathrm{Hg}$ isotope seasonality at station 13.

Unlike at station 13, samples collected at station 98 display a seasonality in their $\mathrm{Hg}$ isotopic compositions, with positive peaks for both odd- and even-MIF in the summer, with values up to 0.78 and $0.15 \%$, respectively. As the range of $\mathrm{Hg}$ concentrations at stations 98 and 13 are similar (i.e., varying from $~ 30$ to $1800 \mathrm{ng}$ $\mathrm{m}^{-3}$ ), this suggests that, in addition to anthropogenic inputs, the $\mathrm{Hg}$ isotopic compositions of aerosols at station 98 may be modified by secondary processes.

\subsection{Secondary Processes That May Impact Atmospheric $\mathrm{Hg}$ Isotope Signatures}

The annual seasonality for the $\delta^{202} \mathrm{Hg}$ and odd-MIF we observe at station 98 presents similarities with the one reported by Huang et al. (2018) in the urban area of Xiamen (China) where the authors measured low $\delta^{202} \mathrm{Hg}$ (i.e., down to $-4 \%$ ) in winter and high $\Delta^{199} \mathrm{Hg}$, up to $0.7 \%$ in summer. This is also in agreement with the $\Delta^{199} \mathrm{Hg}$ seasonality reported by Huang et al. (2016) in the urban area of Beijing that also presents the highest values in summer but differences in the $\delta^{202} \mathrm{Hg}$ seasonality with the corresponding highest values measured during the winter. Finally, our findings are also consistent with the seasonality reported by $\mathrm{Fu}$ et al. (2019) in a forested site with high $\Delta^{199} \mathrm{Hg}$-values, up to $0.82 \%$, in the summer. The authors explained the seasonality by either varying contributions from Hg sources, in particular local anthropogenic ones, or by the longdistance transportation of atmospheric Hg (Huang et al., 2018; Fu et al., 2019). In order to better constrain the potential mechanisms triggering the seasonal variations of $\mathrm{Hg}$ isotope MIF, we elected to separate our results obtained at station 98 into two periods, the summer (i.e., high Hg-MIF) and the remaining seasons (i.e., spring, autumn and winter, thereafter referred as RS). This discrimination is based on the fact that PBM samples during these two periods present distinct $\mathrm{Hg}$ isotopic compositions, with a mean $\Delta^{199} \mathrm{Hg} / \Delta^{201} \mathrm{Hg}$ ratio of $1.63\left(R^{2}=\right.$ $0.84, p$-value $<0.01)$ for RS aerosols and of $1\left(R^{2}=0.89, p\right.$-value $=$ 0.02 ) for summer ones.

\subsubsection{Tropospheric $\mathrm{Hg}^{0}$ Oxidation by Halogen Atoms} Coupled to the experimental results reported by previous studies (Bergquist et al., 2007; Zheng et al., 2009; Sun et al., 2016), we may explain the $\Delta^{199} \mathrm{Hg} / \Delta^{201} \mathrm{Hg}$ ratio of 1.63 we observed for aerosol samples collected during spring, autumn, and winter at station 98 by a two-steps mixing between 1$) \mathrm{Hg}^{\mathrm{II}}$ derived from the oxidation of $\mathrm{Hg}^{0}$ by halogen atoms (i.e., $\mathrm{Br}$ and $\mathrm{Cl}$ ) that isotopically fractionates $\mathrm{Hg}$ isotopes with typical $\Delta^{199} \mathrm{Hg} / \Delta^{201} \mathrm{Hg}$ ratios of $1.63\left(\mathrm{Br}^{-}\right)$or $1.89\left(\mathrm{Cl}^{-}\right)$(Sun et al., 2016), with 2) either primary anthropogenic emissions (see above) or $\mathrm{Hg}$ that has undergone photoreduction that will introduce a typical $\Delta^{199} \mathrm{Hg} / \Delta^{201} \mathrm{Hg}$ ratio varying from 1 to 1.3 for the residual $\mathrm{Hg}^{\mathrm{II}}$ (Bergquist et al., 2007; Zheng et al., 2009). Such mixing will produce $\mathrm{Hg}$ with an intermediate $\Delta^{199} \mathrm{Hg} / \Delta^{201} \mathrm{Hg}$ ratio varying from 1 to 1.89 , which would be consistent with the $\Delta^{199} \mathrm{Hg} / \Delta^{201} \mathrm{Hg}$ ratio of 1.63 that we observed. Furthermore, this high 1.63 ratio suggests that PBM measured during the RS period would be 


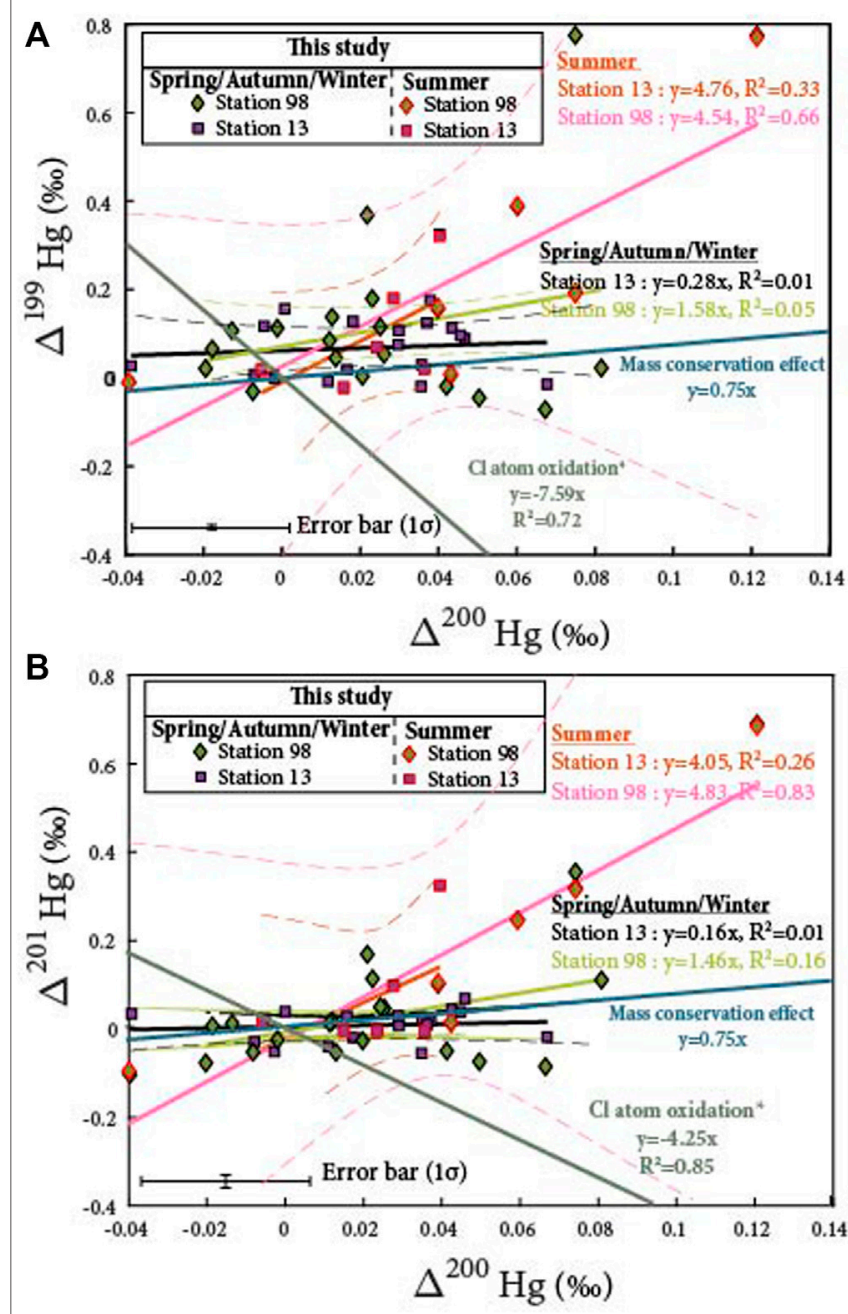

FIGURE 4 | (A) $\Delta^{199} \mathrm{Hg} / \Delta^{200} \mathrm{Hg}$ and (B) $\Delta^{201} \mathrm{Hg} / \Delta^{200} \mathrm{Hg}$ ratios from aerosol samples collected in Montreal. Samples are discriminated following the period of sampling: summer vs autumn/winter/spring. The slope for oxidation by $\mathrm{Cl}$ atoms is deduced from Sun et al. (2016). The calculation for the one corresponding to the mass conservation effect is described in this study. To our knowledge, no corresponding slopes have been reported for the photoreduction and $\mathrm{Br}$ oxidation pathways.

mostly dominated by $\mathrm{Hg}^{\mathrm{II}}$ formed by the oxidation of $\mathrm{Hg}^{0}$ by halogen atoms, and that the contributions from photoreduction and/or anthropogenic emissions would thus be less impactful. The PBM measured during the RS period is also characterized by $\mathrm{Hg}$ isotopic compositions that do not follow any trend in both the $\Delta^{199} \mathrm{Hg} / \Delta^{200} \mathrm{Hg}\left(R^{2}=0.05, p\right.$-value $\left.=0.74\right)$ and $\Delta^{201} \mathrm{Hg} / \Delta^{200} \mathrm{Hg}$ $\left(R^{2}=0.16, p\right.$-value $\left.=0.26\right)$ diagrams. This absence of trends between the odd-MIF and the even-MIF may either reflect that $\mathrm{Br}$ oxidation (Sun et al., 2016), Hg photoreduction (Bergquist et al., 2007; Zheng et al., 2009) and of anthropogenic emissions (Supplementary Figure S1) are involved, suggesting the probable contribution of the latest to the atmospheric PBM in Montreal. However, considering that station 98 is less exposed to anthropogenic emissions (Boulet and Melancon, 2011) as it is also illustrated by the higher concentration of $\mathrm{NO}_{\mathrm{x}}$ in the station 13 than in station 98 (i.e., a mean concentration value of $24 \pm$ $11.8 \mathrm{ppb}$ vs a mean concentration value of $8 \pm 10.8 \mathrm{ppb}$, respectively), we can then hypothesize that the $\mathrm{Hg}$ isotopic compositions measured during the RS period mainly reflect successive oxidation and photoreduction reactions.

\subsubsection{Additional Factors Controlling $\mathrm{Hg}$ Isotopes in Summer}

Summer PBM samples measured at station 98 display $\mathrm{Hg}$ isotopic compositions distinct from the RS ones, with a $\Delta^{199} \mathrm{Hg} / \Delta^{201} \mathrm{Hg}$ ratio of $1.00\left(R^{2}=0.89\right.$; Figure 3), a $\Delta^{201} \mathrm{Hg} / \Delta^{200} \mathrm{Hg}$ ratio of $4.83\left(R^{2}=0.83\right)$, and a $\Delta^{199} \mathrm{Hg} /$ $\Delta^{200} \mathrm{Hg}$ ratio of $4.54\left(R^{2}=0.66\right.$ : Figures $\left.4 \mathbf{A}, \mathbf{B}\right)$. Similarly to station 13 , while a $\Delta^{199} \mathrm{Hg} / \Delta^{201} \mathrm{Hg}$ ratio of 1.00 may result from photoreduction and/or anthropogenic inputs, these two processes cannot explain neither the high $\Delta^{200} \mathrm{Hg}$ values, up to $0.15 \%$, nor the $\Delta^{201} \mathrm{Hg} / \Delta^{200} \mathrm{Hg}$ ratio of 4.83 . This suggests that at least one other process and/or source must be involved. The different hypotheses regarding their characteristics are discussed below.

\subsubsection{Stratospheric Inputs}

Positive $\Delta^{200} \mathrm{Hg}$ have been reported in $\mathrm{PBM}$ and precipitation worldwide, though the mechanisms triggering such even-MIF remain unclear (Gratz et al., 2010; Chen et al., 2012; Demers et al., 2013; Rolison et al., 2013; Demers et al., 2015). Positive $\Delta^{200} \mathrm{Hg}$ anomalies in atmospheric samples have been suggested to result from the photochemical oxidation of $\mathrm{Hg}^{0}$ in the upper troposphere and/or stratosphere (Chen et al., 2012). The hypothesis of a stratospheric input would also account for the positive odd-Hg MIF considering 1) the hypothesis made by Fu et al. (2019) that the photoreduction of aerosols fractionate $\mathrm{Hg}$ isotopes in a similar way to photoreduction in aqueous solutions and 2) that $\mathrm{Hg}$ photoreduction in the stratosphere would occur at a higher magnitude than in the troposphere as more UV irradiations (and wavelengths) are available in the stratosphere (Molina et al., 1986).

To test this hypothesis, we used HYSPLIT to simulate a 3-days back-trajectories for each of our sample. We observed that none of our summer aerosol samples reached an altitude higher than $2000 \mathrm{~m}$ (Supplementary Figure S2). Furthermore, the stratosphere-troposphere exchange (STE) in the Northern Hemisphere close to Montreal is preferentially located in the Northern Pacific and Northern Atlantic (Sprenger and Wernli, 2003; Gettelman et al., 2011; Boothe et al., 2017) and presents higher mass fluxes during the winter than in the summer (i.e., $\sim 250 \mathrm{~kg} \mathrm{~s}^{-1} \mathrm{~km}^{-2}$ vs $\sim 100 \mathrm{~kg} \mathrm{~s}^{-1} \mathrm{~km}^{-2}$, respectively; Boothe et al. (2017)). Thus, as demonstrated by Chen et al. (2012), $\Delta^{200} \mathrm{Hg}$ would be more positive in winter than in summer, which is not what we have been observed. Ultimately, our results demonstrate that a contribution of stratospheric $\mathrm{Hg}$ is highly unlikely, implying that this cannot explain the positive $\Delta^{200} \mathrm{Hg}$ we measured during the summer.

\subsubsection{The Mass Conservation Effect}

Farquhar et al. (2007) discussed the mass conservation effect and demonstrated that this process can generate small MIF, even at 

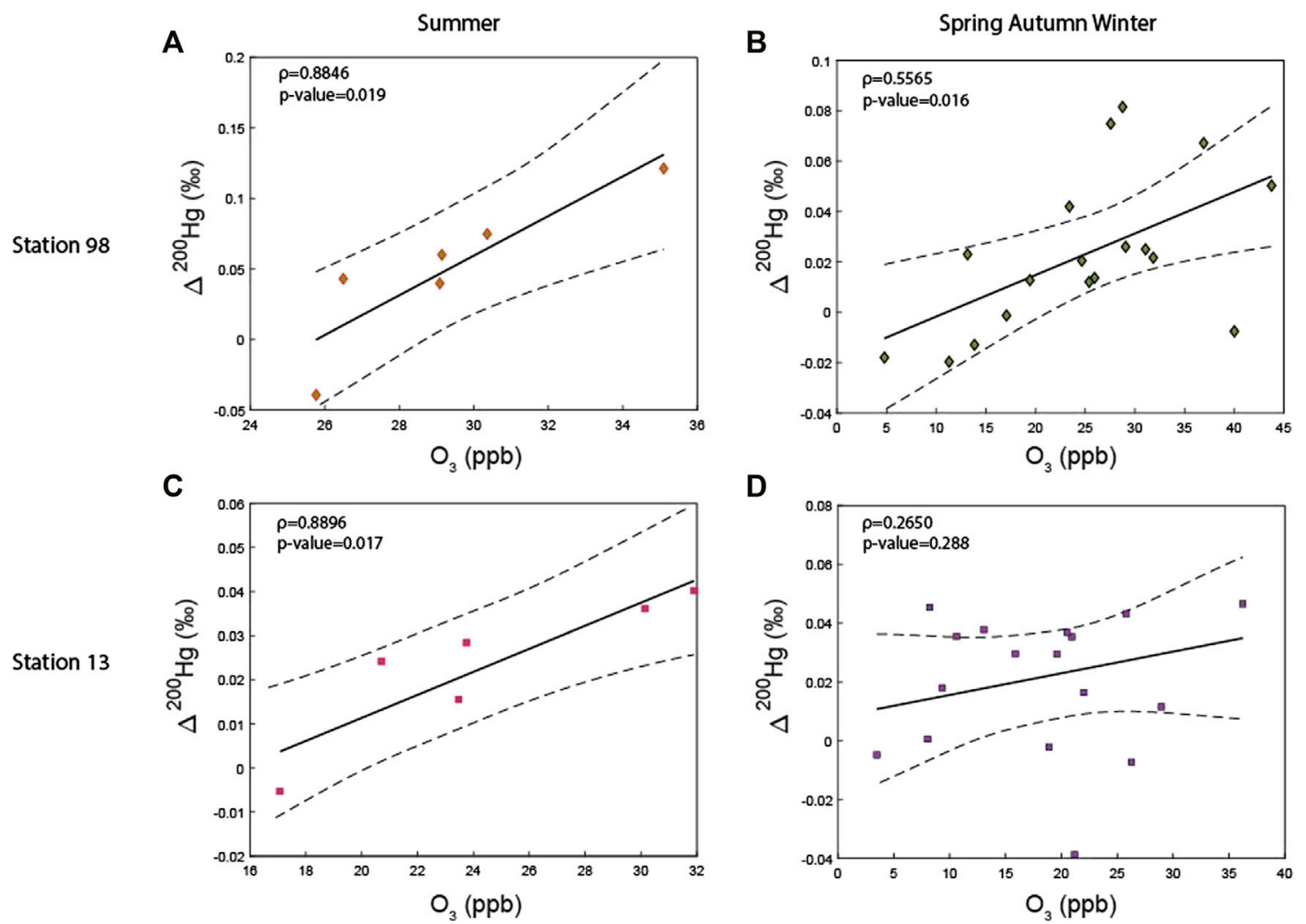

FIGURE 5 | Positive linear relationships observed between $\Delta^{200} \mathrm{Hg}$ and ozone concentrations at station 98 during (A) summer, (B) spring autumn and winter, and at station 13 during (C) summer and (D) spring autumn and winter. The correlation significance is calculated using a Spearman correlation.

equilibrium after mixing. The mass conservation effect has also been shown to play a role in the variations of the $\mathrm{S}$ multi-isotopic compositions in metabolic and biogeochemical networks (Farquhar et al., 2007). We suggest that these small MIF would also occur for $\mathrm{Hg}$ isotopes and produce distinct $\Delta^{199} \mathrm{Hg} / \Delta^{201} \mathrm{Hg}, \Delta^{201} \mathrm{Hg} / \Delta^{200} \mathrm{Hg}$ and $\Delta^{199} \mathrm{Hg} / \Delta^{200} \mathrm{Hg}$ ratios of $1.01,0.74$, and 0.75 , respectively (see Supplementary Materials for more details). Although the $\Delta^{199} \mathrm{Hg} / \Delta^{201} \mathrm{Hg}$ ratio of 1.0 measured at station 98 during the summer yields a value consistent with the one characterizing this mass conservation effect, the corresponding $\Delta^{201} \mathrm{Hg} / \Delta^{200} \mathrm{Hg}$ (4.83) and $\Delta^{199} \mathrm{Hg} /$ $\Delta^{200} \mathrm{Hg}$ (4.54) ratios cannot be explained by this effect. It follows that the mass conservation effect is unlikely responsible for the high $\Delta^{199} \mathrm{Hg}$ and $\Delta^{200} \mathrm{Hg}$ values, of up to 0.78 and $0.15 \%$, that we measured during summer.

\subsubsection{Additional Oxidation Process Involved}

Since none of the aforementioned reactions can explain the high $\Delta^{199} \mathrm{Hg}$ and $\Delta^{200} \mathrm{Hg}$ measured in the summer PBM at station 98 , we suggest that an alternative additional reaction must be involved. We observed that $\Delta^{200} \mathrm{Hg}$ is strongly correlated to ozone $\left(\mathrm{O}_{3}\right)$ concentrations at station 98, both during the summer $(p$-value $=0.02)$ and the RS $(p$-value $=0.02)$ periods (Figure 5). This underlines the possibility of a reaction involving $\mathrm{O}_{3}$. The $\mathrm{Hg}$ oxidation by ozone $\left(\mathrm{O}_{3}\right)$ has actually been identified as a potential pathway to convert atmospheric $\mathrm{Hg}^{0}$ (and $\mathrm{Hg}^{\mathrm{I}}$ ) into reactive gas $\mathrm{Hg}^{\mathrm{II}}$ (RGM) that may ultimately be incorporated into aerosols, thus contributing to the $\mathrm{Hg}$ atmospheric budget (De Simone et al., 2015; Travnikov et al., 2017). Although theoretical doubts remain about its viability and significance for the oxidation of $\mathrm{Hg}^{0}$ (Calvert et al., 2005), a recent study suggested that $\mathrm{O}_{3}$ could be the main oxidant of $\mathrm{Hg}^{\mathrm{I}}$ (Shah et al., 2021). Our hypothesis would also be consistent with the findings of Ren et al. (2014) who highlighted a positive correlation between the concentrations of gaseous oxidized mercury (GOM) and $\mathrm{O}_{3}$ in the Northern Gulf of Mexico. Thus, to our knowledge, this study is the first to highlight a correlation between the ozone concentration and the even-MIF, bringing thus an additional argument that $\mathrm{O}_{3}$ might be involved in $\mathrm{Hg}^{0}$ oxidation.

Still, the variations of the $\mathrm{Hg}$ multi-isotopic compositions measured at station 98 may reflect, at least partially, a seasonal transition from the tropospheric $\mathrm{Hg}^{0}$ oxidation by halogen radicals, from autumn to spring, to an oxidation by ozone process during the summer. This hypothesis is consistent with the fact that tropospheric reactive halogens radicals $(\mathrm{Cl}, \mathrm{Br}$ or $\mathrm{I})$ have been shown to play an important role in the ozone cycle by destroying $\mathrm{O}_{3}$ through catalytic cycles (Chameides et al., 1980) and by decreasing its production rate (Von Glasow et al., 2004). It comes that when halogen atoms are dominating during the RS period, they will represent the major oxidant reservoir for $\mathrm{Hg}^{0}$. In 
contrast, during summer, ozone becomes the dominating source of $\mathrm{Hg}^{0}$ oxidants as its concentrations become higher due to a higher influence of solar radiations during that period. This scenario is also consistent with the findings of Shah et al. (2021) who demonstrated that the two main oxidation pathways involving halogen atoms, $\mathrm{OH}$ and ozone can coexist. Besides, concentrations of atmospheric reactive halogens that are of marine origin have been extensively reported to decrease during the summer (Keene et al., 2007; Gao et al., 2010), leaving room for the ozone concentrations to increase during that period. This emphasizes the importance in future studies of 1) measuring the concentration of halogen atoms and 2) determining the source of halogen atoms at stations 13 and 98 , in order to verify our hypothesis. Furthermore, future experimental studies are still needed to specifically characterize the $\mathrm{Hg}$ multi-isotopic fractionations associated to this $\mathrm{O}_{3}$ oxidation pathway. In that perspective and to account for the $\mathrm{Hg}$ isotopic compositions we measured in Montreal, we predict that $\mathrm{O}_{3}$ oxidation should fractionate $\mathrm{Hg}$ isotopes following a $\Delta^{199} \mathrm{Hg} / \Delta^{201} \mathrm{Hg}$ ratio of $\sim 1$ and $\Delta^{199} \mathrm{Hg} / \Delta^{200} \mathrm{Hg}$ and $\Delta^{201} \mathrm{Hg} /$ $\Delta^{200} \mathrm{Hg}$ ratios both close to 4.5 .

\subsection{Implications and Conclusion}

Our study demonstrates that the current scheme for atmospheric $\mathrm{Hg}$ that only considers anthropogenic emissions, oxidation by halogen atoms and photoreduction cannot account for the whole range of $\mathrm{Hg}$ multi-isotopic compositions we measured in atmospheric PBM in Montreal. Based on the strong correlations we observe between $\Delta^{200} \mathrm{Hg}$ and the ozone concentrations, we suggest that $\mathrm{Hg}$ oxidation involving ozone might represent the missing oxidation pathway. Our results also demonstrate that an approach coupling $\mathrm{Hg}$ isotopic compositions and chemistry discriminates the different oxidation mechanisms controlling the $\mathrm{Hg}$ atmospheric budget. Indeed, as both odd and even-MIF $\mathrm{Hg}$ isotopic compositions cannot be explained by halogen atom oxidation pathways, nor anthropogenic emissions, nor stratospheric inputs, this demonstrates the necessity that another oxidation pathways is involved. In that perspective, integrating the $\mathrm{Hg}$ oxidation by $\mathrm{O}_{3}$ in the current atmospheric models would help better elucidate the $\mathrm{Hg}$ biogeochemical cycle, both in distinct environments and during different seasons, in particular in industrialized urban areas where high $\mathrm{O}_{3}$ concentrations resulting from the photochemical oxidation of VOCs and $\mathrm{CO}$ in the presence of nitrogen oxides $\left(\mathrm{NO}_{\mathrm{x}}\right)$ have been reported. These urban precursors (i.e., VOCs, CO, and $\mathrm{NO}_{\mathrm{x}}$ ) concentrations are higher in industrialized urban areas compared to sub-rural and urban ones (Jia et al., 2008). They are mainly emitted by industrial activities, power plants and road traffic (Li et al., 2017; Zheng et al., 2018; Wang et al., 2019), in particular in emerging countries such as China that has now become a hot spot for urban pollution by ozone (Wang et al., 2017; Lu et al., 2018). Considering that $\mathrm{O}_{3}$ oxidation would be more important in regions characterized by high $\mathrm{O}_{3}$ concentrations, $\mathrm{Hg}^{\mathrm{II}}$ and $\mathrm{PBM}$ concentrations should be expected to be enhanced in these regions due to this oxidation pathways for $\mathrm{Hg}$ coming from non-point sources (Rutter et al., 2008), affecting $\mathrm{Hg}^{\mathrm{II}}$ deposition rates and ultimately $\mathrm{Hg}^{\mathrm{II}}$ fluxes at a global scale. This increase would be thus different from the increase of $\mathrm{Hg}^{\mathrm{II}}$ and PBM observed due to an artifact of sampling as shown by Lynam et al. (2005). Our hypothesis is furthermore supported by the fact that $\mathrm{Hg}^{0}$ oxidation by $\mathrm{O}_{3}$ can exist in the presence of aerosols and is enhanced in areas experiencing high $\mathrm{NO}_{2}$ concentrations (Hong et al., 2016; Gencarelli et al., 2017; Travnikov et al., 2017). As several model studies have shown discrepancies between observed and simulated $\mathrm{Hg}^{\mathrm{II}}$ concentrations, this arises the urgent need to take both the $\mathrm{O}_{3}$ and halogen atom oxidation pathways into account in future atmospheric models (Wang et al., 2018).

Overall, our study demonstrates that the $\mathrm{Hg}$ multiple isotopic compositions provide a reliable complementary proxy of the atmosphere oxidant capacity and of its chemistry that could help improve our understanding of the processes involved ( $\mathrm{Fu}$ et al., 2019; Huang et al., 2019). Still, in order to validate our hypothesis and its significant role in the global $\mathrm{Hg}$ cycle, further experimental studies are needed to better understand the $\mathrm{Hg}$ isotopic fractionations associated to the $\mathrm{Hg}^{0}$ oxidation by ozone.

\section{DATA AVAILABILITY STATEMENT}

The original contributions presented in the study are included in the article/Supplementary Material, further inquiries can be directed to the corresponding authors.

\section{AUTHOR CONTRIBUTIONS}

DAY conducted both mercury isotope and chemical composition measurements under the supervision of JC. DW provided the samples. DAY, JC, ZW, and DW interpreted the data. DAY wrote the paper with contributions from all the coauthors.

\section{FUNDING}

This study was supported by The National Natural Science Foundation of China (Nos. 41830647, 41625012, 41961144028, U1612442) to JC, and the Chinese Academy of Science President's International Fellowship Initiative (PIFI-C, Grant 2018PC0034) to DAY.

\section{SUPPLEMENTARY MATERIAL}

The Supplementary Material for this article can be found online at: https://www.frontiersin.org/articles/10.3389/fenvs.2021.773327/ full\#supplementary-material 


\section{REFERENCES}

Amos, H. M., Jacob, D. J., Holmes, C. D., and Fisher, J. A. (2012). Gas-particle Partitioning of Atmospheric $\mathrm{Hg}$ (II) and its Effect on Global Mercury Deposition. Atmos. Chem. Phys. 12, 4. doi:10.5194/acp-12-591-2012

Bergquist, B. A., and Blum, J. D. (2007). Mass-Dependent and -Independent Fractionation of $\mathrm{Hg}$ Isotopes by Photoreduction in Aquatic Systems. Science 318 (5849), 417-420. doi:10.1126/science.1148050

Biswas, A., Blum, J. D., Bergquist, B. A., Keeler, G. J., and Xie, Z. (2008). Natural Mercury Isotope Variation in Coal Deposits and Organic Soils. Environ. Sci. Technol. 42 (22), 8303-8309. doi:10.1021/es801444b

Blum, J. D., and Bergquist, B. A. (2007). Reporting of Variations in the Natural Isotopic Composition of Mercury. Anal. Bioanal. Chem. 388 (2), 353-359. doi:10.1007/s00216-007-1236-9

Boothe, A. C., and Homeyer, C. R. (2017). Global Large-Scale StratosphereTroposphere Exchange in Modern Reanalyses. Atmos. Chem. Phys. 17 (9), 5537-5559. doi:10.5194/acp-17-5537-2017

Boulet, D., and Melancon, S. (2011). "Bilan environnemental. Qualité de l'air à Montréal," in Rapport Annuel 2011.Ville de Montréal, Service des infrastructures, $d u$ transport et de l'environnement, Direction de l'environnement et du développement durable, Division de la planification et du suivi environnemental (Montreal: RSQA), 8.

Boulet, D., and Melancon, S. (2013). "Bilan environnemental. Qualité de l'air à Montréal," in Rapport Annuel 2013. Ville de Montréal, Service de l'environnement Division de la planification et du suivi environnemental (Montreal: RSQA), 8.

Boulet, D., and Melancon, S. (2012). "Bilan environnemental. Qualité de l'air à Montréal," in Rapport Annuel 2012.Ville de Montréal, Service des infrastructures, $d u$ transport et de l'environnement, Direction de l'environnement et du développement durable, Division de la planification et du suivi environnemental (Montreal: RSQA), 8.

Buchachenko, A. L. (2013). Mass-independent Isotope Effects. J. Phys. Chem. B 117 (8), 2231-2238. doi:10.1021/jp308727w

Cai, H., and Chen, J. (2016). Mass-independent Fractionation of Even Mercury Isotopes. Sci. Bull. 61 (2), 116-124. doi:10.1007/s11434-015-0968-8

Calvert, J., and Lindberg, S. (2005). Mechanisms of Mercury Removal by O and OH in the Atmosphere. Atmos. Environ. 39 (18), 3355-3367. doi:10.1016/ j.atmosenv.2005.01.055

Chameides, W. L., and Davis, D. D. (1980). Iodine: Its Possible Role in Tropospheric Photochemistry. J. Geophys. Res. 85 (C12), 7383-7398. doi:10.1029/jc085ic12p07383

Chen, J., Hintelmann, H., Feng, X., and Dimock, B. (2012). Unusual Fractionation of Both Odd and Even Mercury Isotopes in Precipitation from Peterborough, ON, Canada. Geochimica et Cosmochimica Acta 90, 33-46. doi:10.1016/ j.gca.2012.05.005

Chen, J., Hintelmann, H., Zheng, W., Feng, X., Cai, H., Wang, Z., et al. (2016). Isotopic Evidence for Distinct Sources of Mercury in lake Waters and Sediments. Chem. Geology. 426, 33-44. doi:10.1016/j.chemgeo.2016.01.030

Das, R., Wang, X., Khezri, B., and Webster, R. (2016). Mercury Isotopes of Atmospheric Particle Bound Mercury for Source Apportionment Study in Urban Kolkata, India. Elem. Sci. Anth 4, 1. doi:10.12952/ journal.elementa.000098

Dauphas, N., and Schauble, E. A. (2016). Mass Fractionation Laws, Massindependent Effects, and Isotopic Anomalies. Annu. Rev. Earth Planet. Sci. 44, 709-783. doi:10.1146/annurev-earth-060115-012157

De Simone, F., Cinnirella, S., Gencarelli, C. N., Yang, X., Hedgecock, I. M., and Pirrone, N. (2015). Model Study of Global Mercury Deposition from Biomass Burning. Environ. Sci. Technol. 49 (11), 6712-6721. doi:10.1021/acs.est.5b00969

Demers, J. D., Blum, J. D., and Zak, D. R. (2013). Mercury Isotopes in a Forested Ecosystem: Implications for Air-Surface Exchange Dynamics and the Global Mercury Cycle. Glob. Biogeochem. Cycles 27 (1), 222-238. doi:10.1002/ gbc. 20021

Demers, J. D., Sherman, L. S., Blum, J. D., Marsik, F. J., and Dvonch, J. T. (2015). Coupling Atmospheric Mercury Isotope Ratios and Meteorology to Identify Sources of Mercury Impacting a Coastal Urban-Industrial Region Near Pensacola, Florida, USA. Glob. Biogeochem. Cycles 29 (10), 1689-1705. doi:10.1002/2015gb005146
Estrade, N., Carignan, J., Sonke, J. E., and Donard, O. F. X. (2009). Mercury Isotope Fractionation during Liquid-Vapor Evaporation Experiments. Geochimica et Cosmochimica Acta 73 (10), 2693-2711. doi:10.1016/j.gca.2009.01.024

Farquhar, J., Johnston, D. T., and Wing, B. A. (2007). Implications of Conservation of Mass Effects on Mass-dependent Isotope Fractionations: Influence of Network Structure on Sulfur Isotope Phase Space of Dissimilatory Sulfate Reduction. Geochimica et Cosmochimica Acta 71 (24), 5862-5875. doi:10.1016/ j.gca.2007.08.028

Farquhar, J., and Wing, B. A. (2003). Multiple Sulfur Isotopes and the Evolution of the Atmosphere. Earth Planet. Sci. Lett. 213 (1), 1-13. doi:10.1016/s0012$821 \times(03) 00296-6$

Fu, X., Jiskra, M., Yang, X., Marusczak, N., Enrico, M., Chmeleff, J., et al. (2021). Mass-Independent Fractionation of Even and Odd Mercury Isotopes during Atmospheric Mercury Redox Reactions. Environ. Sci. Technol. 55 (14), 10164-10174. doi:10.1021/acs.est.1c02568

Fu, X., Marusczak, N., Wang, X., Gheusi, F., and Sonke, J. E. (2016). Isotopic Composition of Gaseous Elemental Mercury in the Free Troposphere of the Pic du Midi Observatory, France. Environ. Sci. Technol. 50 (11), 5641-5650. doi:10.1021/acs.est.6b00033

Fu, X., Zhang, H., Feng, X., Tan, Q., Ming, L., Liu, C., et al. (2019). Domestic and Transboundary Sources of Atmospheric Particulate Bound Mercury in Remote Areas of China: Evidence from Mercury Isotopes. Environ. Sci. Technol. 53 (4), 1947-1957. doi:10.1021/acs.est.8b06736

Gao, Y., Sun, M., Wu, X., Liu, Y., Guo, Y., and Wu, J. (2010). Concentration Characteristics of Bromine and Iodine in Aerosols in Shanghai, China. Atmos. Environ. 44 (34), 4298-4302. doi:10.1016/j.atmosenv.2010.05.047

Gencarelli, C. N., Bieser, J., Carbone, F., De Simone, F., Hedgecock, I. M., Matthias, V., et al. (2017). Sensitivity Model Study of Regional Mercury Dispersion in the Atmosphere. Atmos. Chem. Phys. 17 (1), 627-643. doi:10.5194/acp-17-627-2017

Geng, H., Yin, R., and Li, X. (2018). An Optimized Protocol for High Precision Measurement of $\mathrm{Hg}$ Isotopic Compositions in Samples with Low Concentrations of $\mathrm{Hg}$ Using MC-ICP-MS. J. Anal. Spectrom. 33 (11), 1932-1940. doi:10.1039/c8ja00255j

Gettelman, A., Hoor, P., Pan, L. L., and Randel, W. J. (2011). The Extratropical Upper Troposphere and Lower Stratosphere. Rev. Geophys. 49 (3), 1. doi:10.1029/2011rg000355

Gratz, L. E., Keeler, G. J., Blum, J. D., and Sherman, L. S. (2010). Isotopic Composition and Fractionation of Mercury in Great Lakes Precipitation and Ambient Air. Environ. Sci. Technol. 44 (20), 7764-7770. doi:10.1021/es100383w

Holmes, C. D., Jacob, D. J., Corbitt, E. S., and Mao, J. (2010). Global Atmospheric Model for Mercury Including Oxidation by Bromine Atoms. Atmos. Chem. Phys. 10, 1. doi:10.5194/acp-10-12037-2010

Hong, Q., Xie, Z., Liu, C., Wang, F., Xie, P., Kang, H., et al. (2016). Speciated Atmospheric Mercury on Haze and Non-haze Days in an Inland City in China. Atmos. Chem. Phys. 16 (21), 13807-13821. doi:10.5194/acp-16-13807-2016

Horowitz, H. M., Jacob, D. J., Zhang, Y., Dibble, T. S., Slemr, F., Amos, H. M., et al. (2017). A New Mechanism for Atmospheric Mercury Redox Chemistry: Implications for the Global Mercury Budget. Atmos. Chem. Phys. 17 (10), 6353-6371. doi:10.5194/acp-17-6353-2017

Huang, Q., Chen, J., Huang, W., Fu, P., Guinot, B., Feng, X., et al. (2016). Isotopic Composition for Source Identification of Mercury in Atmospheric fine Particles. Atmos. Chem. Phys. 16 (18), 11773-11786. doi:10.5194/acp-16-11773-2016

Huang, Q., Chen, J., Huang, W., Reinfelder, J. R., Fu, P., Yuan, S., et al. (2019). Diel Variation in Mercury Stable Isotope Ratios Records Photoreduction of PM2.5bound Mercury. Atmos. Chem. Phys. 19 (1), 315-325. doi:10.5194/acp-19-3152019

Huang, Q., Liu, Y., Chen, J., Feng, X., Huang, W., Yuan, S., et al. (2015). An Improved Dual-Stage Protocol to Pre-concentrate Mercury from Airborne Particles for Precise Isotopic Measurement. J. Anal. Spectrom. 30 (4), 957-966. doi:10.1039/c4ja00438h

Huang, S., Sun, L., Zhou, T., Yuan, D., Du, B., and Sun, X. (2018). Natural Stable Isotopic Compositions of Mercury in Aerosols and Wet Precipitations Around a Coal-Fired Power Plant in Xiamen, Southeast China. Atmos. Environ. 173, 72-80. doi:10.1016/j.atmosenv.2017.11.003

Jia, C., Batterman, S., and Godwin, C. (2008). VOCs in Industrial, Urban and Suburban Neighborhoods, Part 1: Indoor and Outdoor Concentrations, Variation, and Risk Drivers. Atmos. Environ. 42 (9), 2083-2100. doi:10.1016/j.atmosenv.2007.11.055 
Keene, W. C., Stutz, J., Pszenny, A., and Maben, J. R. (2007). Inorganic Chlorine and Bromine in Coastal New England Air during Summer. J. Geophys. Res. Atmospheres 112 (D10), 1. doi:10.1029/2006jd007689

Kurien, U., Hu, Z., Lee, H., Dastoor, A. P., and Ariya, P. A. (2017). Radiation Enhanced Uptake of $\mathrm{Hg} 0(\mathrm{~g})$ on Iron (Oxyhydr)oxide Nanoparticles. RSC Adv. 7 (71), 45010-45021. doi:10.1039/c7ra07401h

Li, M., Zhang, Q., Kurokawa, J.-i., Woo, J.-H., He, K., Lu, Z., et al. (2017). MIX: a Mosaic Asian Anthropogenic Emission Inventory under the International Collaboration Framework of the MICS-Asia and HTAP. Atmos. Chem. Phys. 17 (2), 935-963. doi:10.5194/acp-17-935-2017

Lu, X., Hong, J., Zhang, L., Cooper, O. R., Schultz, M. G., Xu, X., et al. (2018). Severe Surface Ozone Pollution in China: A Global Perspective. Environ. Sci. Technol. Lett. 5 (8), 487-494. doi:10.1021/acs.estlett.8b00366

Lynam, M., and Keeler, G. (2005). Artifacts Associated with the Measurement of Particulate Mercury in an Urban Environment: The Influence of Elevated Ozone Concentrations. Atmos. Environ. 39 (17), 3081-3088. doi:10.1016/ j.atmosenv.2005.01.036

Mead, C., Lyons, J. R., Johnson, T. M., and Anbar, A. D. (2013). Unique Hg Stable Isotope Signatures of Compact Fluorescent Lamp-Sourced Hg. Environ. Sci. Technol. 47 (6), 2542-2547. doi:10.1021/es303940p

Molina, L. T., and Molina, M. J. (1986). Absolute Absorption Cross Sections of Ozone in the 185- to 350-nm Wavelength Range. J. Geophys. Res. 91 (D13), 14501-14508. doi:10.1029/jd091id13p14501

Paris, R., Desboeufs, K. V., Formenti, P., Nava, S., and Chou, C. (2010). Chemical Characterisation of Iron in Dust and Biomass Burning Aerosols during AMMA-SOP0/DABEX: Implication for Iron Solubility. Atmos. Chem. Phys. 10 (9), 4273-4282. doi:10.5194/acp-10-4273-2010

Qiu, Y., Gai, P., Yue, F., Zhang, Y., He, P., Kang, H., et al. (2021). Identification of Potential Sources of Elevated PM2.5-Hg Using Mercury Isotopes during Haze Events. Atmos. Environ. 247, 118203. doi:10.1016/j.atmosenv.2021.118203

Ren, X., Luke, W., Kelley, P., Cohen, M., Ngan, F., Artz, R., et al. (2014). Mercury Speciation at a Coastal Site in the Northern Gulf of Mexico: Results from the Grand Bay Intensive Studies in Summer 2010 and spring 2011. Atmosphere 5 (2), 230-251. doi:10.3390/atmos5020230

Rolison, J. M., Landing, W. M., Luke, W., Cohen, M., and Salters, V. J. M. (2013). Isotopic Composition of Species-specific Atmospheric $\mathrm{Hg}$ in a Coastal Environment. Chem. Geology. 336, 37-49. doi:10.1016/j.chemgeo.2012.10.007

Rutter, A. P., Schauer, J. J., Lough, G. C., Snyder, D. C., Kolb, C. J., Von Klooster, S., et al. (2008). A Comparison of Speciated Atmospheric Mercury at an Urban center and an Upwind Rural Location. J. Environ. Monit. 10 (1), 102-108. doi:10.1039/b710247j

Saiz-Lopez, A., Sitkiewicz, S. P., Roca-Sanjuán, D., Oliva-Enrich, J. M., Dávalos, J. Z., Notario, R., et al. (2018). Photoreduction of Gaseous Oxidized Mercury Changes Global Atmospheric Mercury Speciation, Transport and Deposition. Nat. Commun. 9 (1), 4796. doi:10.1038/s41467-018-07075-3

Seigneur, C. (1998). Mercury Adsorption to Elemental Carbon (Soot) Particles and Atmospheric Particulate Matter. Atmos. Environ. 32 (14-15), 2649-2657. doi:10.1016/s1352-2310(97)00415-9

Selin, N. E. (2009). Global Biogeochemical Cycling of Mercury: A Review. Annu. Rev. Environ. Resour. 34 (1), 43-63. doi:10.1146/ annurev.environ.051308.084314

Shah, V., Jacob, D. J., Thackray, C. P., Wang, X., Sunderland, E. M., Dibble, T. S., et al. (2021). Improved Mechanistic Model of the Atmospheric Redox Chemistry of Mercury. Environ. Sci. Tech. 55 (21), 14445-14456. doi:10.1021/acs.est.1c03160

Sherman, L. S., Blum, J. D., Johnson, K. P., Keeler, G. J., Barres, J. A., and Douglas, T. A. (2010). Mass-independent Fractionation of Mercury Isotopes in Arctic Snow Driven by Sunlight. Nat. Geosci 3, 173-177. doi:10.1038/ngeo758

Si, L., and Ariya, P. (2018). Recent Advances in Atmospheric Chemistry of Mercury. Atmosphere 9 (2), 76. doi:10.3390/atmos 9020076

Sprenger, M., and Wernli, H. (2003). A Northern Hemispheric Climatology of Cross-tropopause Exchange for the ERA15 Time Period (1979-1993). J. Geophys. Res. Atmospheres 108 (D12). doi:10.1029/2002jd002636

Subir, M., Ariya, P. A., and Dastoor, A. P. (2012). A Review of the Sources of Uncertainties in Atmospheric Mercury Modeling II. Mercury Surface and Heterogeneous Chemistry - A Missing Link. Atmos. Environ. 46, 1-10. doi:10.1016/j.atmosenv.2011.07.047

Sun, G., Sommar, J., Feng, X., Lin, C.-J., Ge, M., Wang, W., et al. (2016). MassDependent and -Independent Fractionation of Mercury Isotope during Gas- phase Oxidation of Elemental Mercury Vapor by Atomic $\mathrm{Cl}$ and Br. Environ. Sci. Technol. 50 (17), 9232-9241. doi:10.1021/acs.est.6b01668

Sun, R., Enrico, M., Heimbürger, L.-E., Scott, C., and Sonke, J. E. (2013). A DoubleStage Tube Furnace-Acid-Trapping Protocol for the Pre-concentration of Mercury from Solid Samples for Isotopic Analysis. Anal. Bioanal. Chem. 405 (21), 6771-6781. doi:10.1007/s00216-013-7152-2

Sun, R., Sonke, J. E., Heimbürger, L.-E., Belkin, H. E., Liu, G., Shome, D., et al. (2014). Mercury Stable Isotope Signatures of World Coal Deposits and Historical Coal Combustion Emissions. Environ. Sci. Technol. 48 (13), 7660-7668. doi:10.1021/es501208a

Sunderland, E. M. (2007). Mercury Exposure from Domestic and Imported Estuarine and marine Fish in the U.S. Seafood Market. Environ. Health Perspect. 115 (2), 235-242. doi:10.1289/ehp.9377

Travnikov, O., Angot, H., Artaxo, P., Bencardino, M., Bieser, J., D’Amore, F., et al. (2017). Multi-model Study of Mercury Dispersion in the Atmosphere: Atmospheric Processes and Model Evaluation. Atmos. Chem. Phys. 17 (8), 5271-5295. doi:10.5194/acp-17-5271-2017

Von Glasow, R., von Kuhlmann, R., Lawrence, M. G., Platt, U., and Crutzen, P. J. (2004). Impact of Reactive Bromine Chemistry in the Troposphere. Atmos. Chem. Phys. 4 (11/12), 2481-2497. doi:10.5194/acp-4-2481-2004

Wang, P., Chen, Y., Hu, J., Zhang, H., and Ying, Q. (2019). Source Apportionment of Summertime Ozone in China Using a Source-Oriented Chemical Transport Model. Atmos. Environ. 211, 79-90. doi:10.1016/j.atmosenv.2019.05.006

Wang, T., Xue, L., Brimblecombe, P., Lam, Y. F., Li, L., and Zhang, L. (2017). Ozone Pollution in China: A Review of Concentrations, Meteorological Influences, Chemical Precursors, and Effects. Sci. Total Environ. 575, 1582-1596. doi:10.1016/j.scitotenv.2016.10.081

Wang, X., Lin, C.-J., Feng, X., Yuan, W., Fu, X., Zhang, H., et al. (2018). Assessment of Regional Mercury Deposition and Emission Outflow in Mainland China. J. Geophys. Res. Atmos. 123 (17), 9868-9890. doi:10.1029/2018jd028350

Wang, X., Luo, J., Yin, R., Yuan, W., Lin, C.-J., Sommar, J., et al. (2017). Using Mercury Isotopes to Understand Mercury Accumulation in the Montane Forest Floor of the Eastern Tibetan Plateau. Environ. Sci. Technol. 51 (2), 801-809. doi:10.1021/acs.est.6b03806

Wang, Z., Chen, J., Feng, X., and Hintelmann, H. (2015). Mass-dependent and Massindependent Fractionation of Mercury Isotopes in Precipitation from Guiyang, SW China. Comptes Rendus Geosci. 347 (7), 358-367. doi:10.1016/j.crte.2015.02.006

World Health Organization (2016). Ambient (Outdoor) Air Quality and Health. Geneva: WHO 1.

Xiao, Z. F., Munthe, J., and Lindqvist, O. (1991). Sampling and Determination of Gaseous and Particulate Mercury in the Atmosphere Using Gold-Coated Denuders. Water Air Soil Pollut. 56 (1), 141-151. doi:10.1007/bf00342268

Xu, H. M., Sun, R. Y., Cao, J. J., Huang, R.-J., Guinot, B., Shen, Z. X., et al. (2019). Mercury Stable Isotope Compositions of Chinese Urban fine Particulates in winter Haze Days: Implications for Hg Sources and Transformations. Chem. Geology. 504, 267-275. doi:10.1016/j.chemgeo.2018.11.018

Xu, H., Sonke, J. E., Guinot, B., Fu, X., Sun, R., Lanzanova, A., et al. (2017). Seasonal and Annual Variations in Atmospheric $\mathrm{Hg}$ and $\mathrm{Pb}$ Isotopes in Xi'an, China. Environ. Sci. Technol. 51 (7), 3759-3766. doi:10.1021/acs.est.6b06145

Yin, R., Feng, X., and Chen, J. (2014). Mercury Stable Isotopic Compositions in Coals from Major Coal Producing Fields in China and Their Geochemical and Environmental Implications. Environ. Sci. Technol. 48 (10), 5565-5574. doi: $10.1021 / \mathrm{es} 500322 \mathrm{n}$

Yin, R., Krabbenhoft, D. P., Bergquist, B. A., Zheng, W., Lepak, R. F., and Hurley, J. P. (2016). Effects of Mercury and Thallium Concentrations on High Precision Determination of Mercury Isotopic Composition by Neptune Plus Multiple Collector Inductively Coupled Plasma Mass Spectrometry. J. Anal. Spectrom. 31 (10), 2060-2068. doi:10.1039/c6ja00107f

Young, E. D., Galy, A., and Nagahara, H. (2002). Kinetic and Equilibrium Massdependent Isotope Fractionation Laws in Nature and Their Geochemical and Cosmochemical Significance. Geochimica et Cosmochimica Acta 66 (6), 1095-1104. doi:10.1016/s0016-7037(01)00832-8

Yu, B., Fu, X., Yin, R., Zhang, H., Wang, X., Lin, C.-J., et al. (2016). Isotopic Composition of Atmospheric Mercury in China: New Evidence for Sources and Transformation Processes in Air and in Vegetation. Environ. Sci. Technol. 50 (17), 9262-9269. doi:10.1021/acs.est.6b01782

Yuan, S., Chen, J., Cai, H., Yuan, W., Wang, Z., Huang, Q., et al. (2018). Sequential Samples Reveal Significant Variation of Mercury Isotope Ratios during Single 
Rainfall Events. Sci. total Environ 624, 133-144. doi:10.1016/ j.scitotenv.2017.12.082

Yuan, S., Zhang, Y., Chen, J., Kang, S., Zhang, J., Feng, X., et al. (2015). Large Variation of Mercury Isotope Composition during a Single Precipitation Event at Lhasa City, Tibetan Plateau, China. Proced. Earth Planet. Sci. 13, 282-286. doi:10.1016/j.proeps.2015.07.066

Zhang, Y., Chen, J., Zheng, W., Sun, R., Yuan, S., Cai, H., et al. (2020). Mercury Isotope Compositions in Large Anthropogenically Impacted Pearl River, South China. Ecotoxicology Environ. Saf. 191, 110229. doi:10.1016/ j.ecoenv.2020.110229

Zheng, B., Tong, D., Li, M., Liu, F., Hong, C., Geng, G., et al. (2018). Trends in China's Anthropogenic Emissions since 2010 as the Consequence of Clean Air Actions. Atmos. Chem. Phys. 18 (19), 14095-14111. doi:10.5194/acp-18-140952018

Zheng, W., and Hintelmann, H. (2010). Isotope Fractionation of Mercury during its Photochemical Reduction by Low-Molecular-Weight Organic Compounds. J. Phys. Chem. A. 114 (12), 4246-4253. doi:10.1021/jp9111348

Zheng, W., and Hintelmann, H. (2009). Mercury Isotope Fractionation during Photoreduction in Natural Water Is Controlled by its $\mathrm{Hg} / \mathrm{DOC}$ Ratio. Geochimica et Cosmochimica Acta 73 (22), 6704-6715. doi:10.1016/ j.gca.2009.08.016
Zheng, W., Obrist, D., Weis, D., and Bergquist, B. A. (2016). Mercury Isotope Compositions across North American Forests. Glob. Biogeochem. Cycles 30 (10), 1475-1492. doi:10.1002/2015gb005323

Conflict of Interest: The authors declare that the research was conducted in the absence of any commercial or financial relationships that could be construed as a potential conflict of interest.

Publisher's Note: All claims expressed in this article are solely those of the authors and do not necessarily represent those of their affiliated organizations, or those of the publisher, the editors and the reviewers. Any product that may be evaluated in this article, or claim that may be made by its manufacturer, is not guaranteed or endorsed by the publisher.

Copyright (c) 2022 AuYang, Chen, Zheng, Lang, Wang, Wang, Zhang, Liu, Zhang, Cai, Yuan and Widory. This is an open-access article distributed under the terms of the Creative Commons Attribution License (CC BY). The use, distribution or reproduction in other forums is permitted, provided the original author(s) and the copyright owner(s) are credited and that the original publication in this journal is cited, in accordance with accepted academic practice. No use, distribution or reproduction is permitted which does not comply with these terms. 